Florida International University FIU Digital Commons

$11-9-2012$

\title{
Preparation of an Immunosorbent and its use in the Solid Phase Extraction of Benzodiazepines
}

Jorge E. Quintana

Florida International University, jquin027@fiu.edu

DOI: $10.25148 /$ etd.FI12113009

Follow this and additional works at: https://digitalcommons.fiu.edu/etd

\section{Recommended Citation}

Quintana, Jorge E., "Preparation of an Immunosorbent and its use in the Solid Phase Extraction of Benzodiazepines" (2012). FIU Electronic Theses and Dissertations. 758.

https://digitalcommons.fiu.edu/etd/758 


\section{FLORIDA INTERNATIONAL UNIVERSITY \\ Miami, Florida}

PREPARATION OF AN IMMUNOSORBENT AND ITS USE IN THE SOLID PHASE EXTRACTION OF BENZODIAZEPINES

A thesis submitted in partial fulfillment of the

requirements for the degree of

MASTER OF SCIENCE

in

CHEMISTRY

by

Jorge E. Quintana

2012 
To: Dean Kenneth Furton

College of Arts and Sciences

This thesis, written by Jorge E. Quintana, and entitled Preparation of an Immunosorbent and its use in the Solid Phase Extraction of Benzodiazepines, having been approved in respect to style and intellectual content, is referred to you for judgment.

We have read this thesis and recommend that it be approved.

Kathleen Rein

Yong Cai

Bruce McCord, Major Professor

Date of Defense: November 9, 2012

The thesis of Jorge E. Quintana is approved

Dean Kenneth Furton
College of Arts and Sciences

Florida International University, 2012 


\section{ACKNOWLEDGMENTS}

I would like to thank my wife for supporting me through my studies.

I would like to thank my advisor Dr. Bruce McCord for his help, support and for encourage me to pursue my line of research. I will always be grateful for his mentorship. Special thanks to the members of my thesis committee Dr Kathleen Rein and Dr.Yong Cai. Their valuable insights and suggestions have greatly improved the work presented within this thesis.

I would like to thank Inge Corbin for training me on the operation of the CE-MS instrument, and for helping me those Saturdays and Sundays when the instrument was out of control, Thanks Inge, I really appreciate your help.

I would like to thank Beckman-Coulter for its financial aid, and for let me gain knowledge and practice in the biomedical field.

Sincere thanks to everyone who helped me make my dream a reality. 


\title{
ABSTRACT OF THE THESIS \\ PREPARATION OF AN IMMUNOSORBENT AND ITS USE IN THE \\ SOLID PHASE EXTRACTION OF BENZODIAZEPINES.
}

\author{
by \\ Jorge E. Quintana \\ Florida International University, 2012 \\ Miami, Florida

\section{Professor Bruce McCord, Major Professor}

The use of capillary electrophoresis (CE) has been restricted to applications having high sample concentrations because of its low sensitivity caused by small injection volumes and, when ultraviolet (UV) detection is used, the short optical path length. Sensitivity in CE can be improved by using more sensitive detection systems, or by preconcentration techniques which are based on chromatographic and/or electrophoretic principles. One of the promising strategies to improve sensitivity is solid phase extraction (SPE). Solid Phase Extraction utilizes high sample volumes and a variety of complex matrixes to facilitate trace detection. To increase the specificity of the SPE a selective solid phase must be chosen. Immunosorbents, which are a combination of an antibody and a solid support, have proven to be an excellent option because of high selectivity of the antibody. This thesis is an exploratory study of the application of immunosorbent-SPE combined with CE for trace concentration of benzodiazepines.

This research describes the immobilization and performance evaluation of an immunosorbent prepared by immobilizing a benzodiazepine-specific antibody on aminopropyl silica. The binding capacity of the immunosorbent, measured as $\mu \mathrm{g}$ of 
benzodiazepine/ gram of immunosorbent, was $39 \pm 10$. The long term stability of the prepared immunosorbent has been improved by capping the remaining aminopropyl groups by reaction with acetic anhydride. The capped immunosorbent retained its binding capacity after several uses. 


\section{TABLE OF CONTENT}

CHAPTER

PAGE

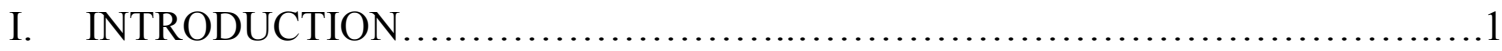

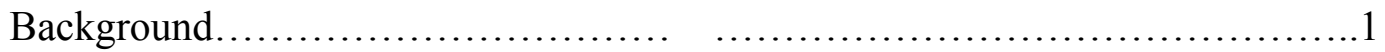

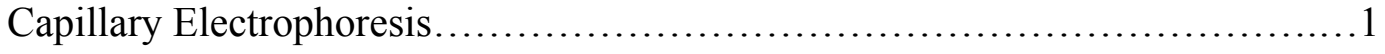

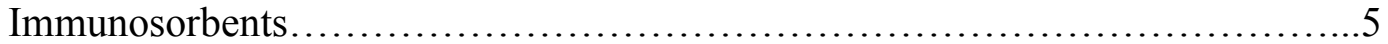

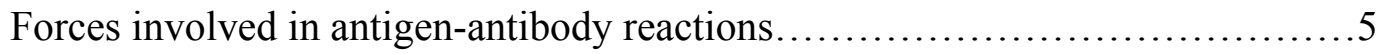

Antibodies................................................................. 7

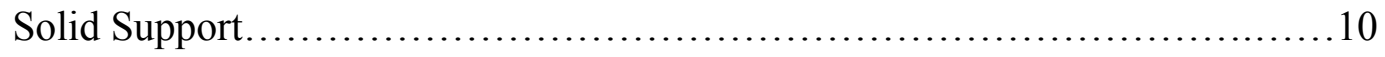

Silica Activation........................................................ 11

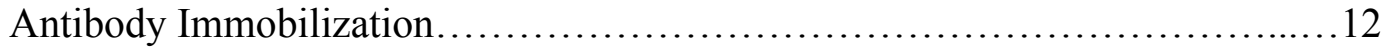

Applications of immunosorbents......................................... 15

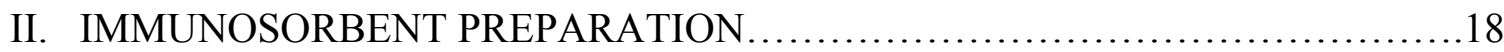

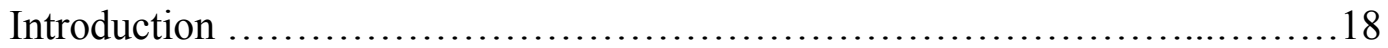

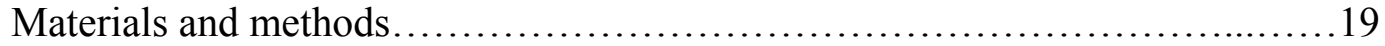

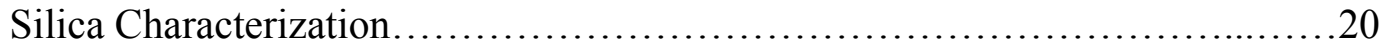

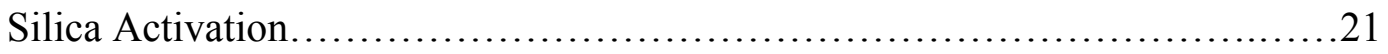

Antibody Characterization............................................. 21

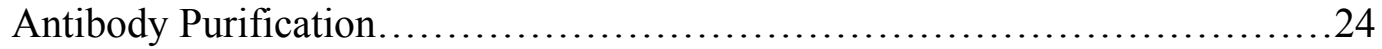

Antibody Activation..................................................... 24

Attachment of the Antibody to Silica.........................................

Results and Discussion................................................... 32

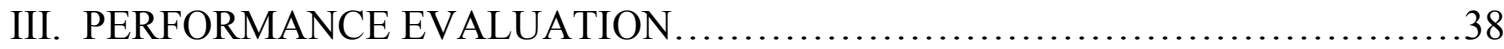

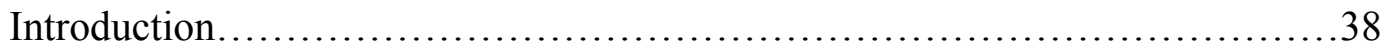

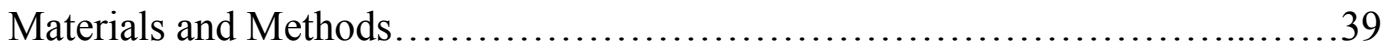

Antibody Binding Assay ................................................. 40

Immunosorbent Binding Assay ...........................................41

Elution testing for the immunosorbent...................................43

Results and Discussion................................................43

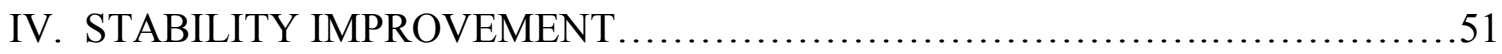

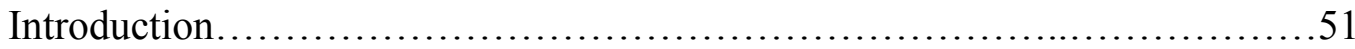

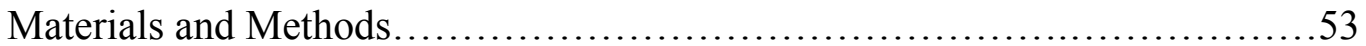

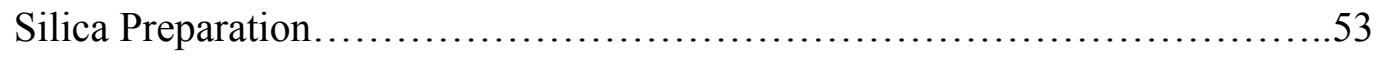

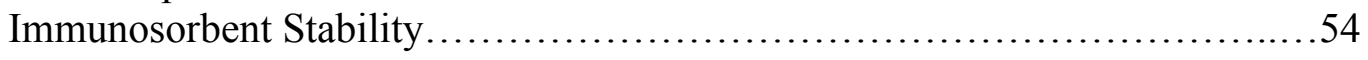

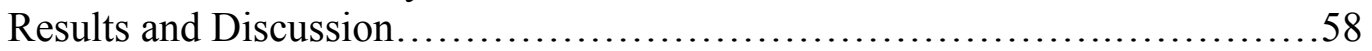

V. CONCLUSIONS AND FUTURE DIRECTIONS ............................62

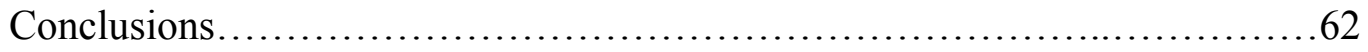

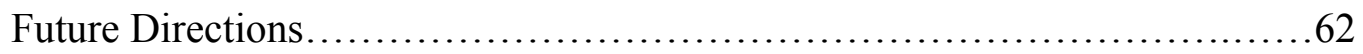

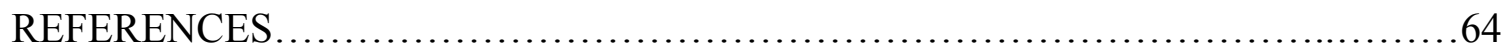




\section{LIST OF FIGURES}

FIGURE

PAGE

1. Structure of Benzodiazepines...........................................

2. Reaction of amino groups with trinitro benzenesulfonic acid (TNBS) .............23

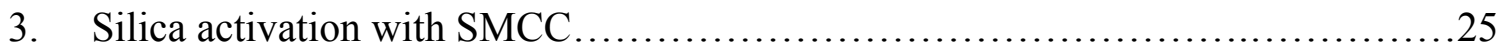

4. Linear regression analysis for protein determination........................... 26

5. Linear regression for analysis of amino groups on proteins $\ldots \ldots \ldots \ldots \ldots \ldots \ldots \ldots \ldots \ldots \ldots \ldots \ldots$

6. Determination of purity in crude antibody by SDS-PAGE $\ldots \ldots \ldots \ldots \ldots \ldots \ldots \ldots \ldots \ldots$

7. Calibration curve for $\log _{10}$ of molecular mass against $\mathrm{Rf}$ by SDS-PAGE...........29

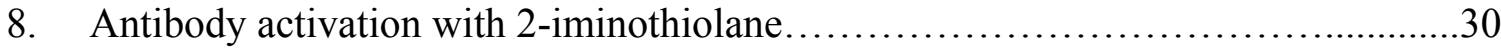

9. Antibody-silica attachment....................................................

10. Calibration curve for flunitrazepam in the range from 1.25 to $15 \mu \mathrm{g} / \mathrm{ml} \ldots \ldots \ldots . . .42$

11. Ion electrochromatogram of $5 \mu \mathrm{g} / \mathrm{ml}$ flunitrazepam standard....................48

12. Ion electrochromatogram of extracted flunitrazepam.........................49

13. Calibration curve for diazepam in the range from 1.25 to $10 \mu \mathrm{g} / \mathrm{ml} \ldots \ldots \ldots \ldots . . . .55$

14. Reproducibility testing for the capped diazepam immunosorbent................57 


\section{Chapter I: Introduction}

Because of the poor concentration limits of detection achieved with capillary electrophoresis (CE), its use has been restricted to analysis at high levels of concentration. To overcome this weakness several strategies have been proposed. One of them, solid phase extraction (SPE) is a promising strategy because allows for the use of high sample volumes and with complex matrixes. To increase the robustness of SPE, a selective solid phase must be chosen. Immunosorbents, which comprise an antibody with a solid support, have proven to be an excellent option because of the high selectivity of the antibody. In order to develop a successful technique, proper interfacing of the immunosorbent and the CE must be performed. My thesis describes an application of immunosorbent-CE for trace concentration of benzodiazepines. To do so, an immunosorbent was prepared by coupling of amino silica with a benzodiazepine-specific antibody and its binding capacity, and its stability were evaluated.

\section{Background}

\section{Capillary electrophoresis:}

Capillary electrophoresis (CE) is a very popular, widely accepted analytical technique for separation. Its success is because of its ability to determine different analytes simultaneously with high efficiency, high resolution, low sample consumption, and short analysis time.

Separation by electrophoresis is obtained by differential migration of solutes in an electrical field. In CE, electrophoresis is performed in narrow-bore capillaries (25-75 $\mu \mathrm{m}$ inner diameter), which are usually filled with buffer. The use of capillaries has numerous advantages over other techniques, particularly with respect to detrimental effects of Joule 
heating. The high electrical resistance of the capillary enables the application of very high electrical fields with only minimal heat generation. Moreover, the large surface area-tovolume ratio of the capillary efficiently dissipates the heat that is generated. The use of the high electrical fields results in short analysis times and high efficiency and resolution. Peak efficiency, often in excess of $10^{5}$ theoretical plates, is the result of the plug profile of the electroosmotic flow, an electrophoretic phenomenon that generates the bulk flow of solution within the capillary. ${ }^{1}$

It is well known that CE usually suffers from poor concentration sensitivity, especially in the most widely used ultraviolet (UV) absorbance detection because of the short optical path length and the low volume of material analyzed. To improve sensitivity in CE, several strategies have been proposed. Most use more sensitive detection systems and/or increasing the sample volumes injected into the electrophoresis medium. Although highly sensitive methods of detection are available (e.g., laser-induced fluorescence, mass spectrometry), they are also highly selective and expensive, so UV absorbance detection is still the most widely used. When CE is used with UV detection, the best way to increase the detection signal is to raise the concentration of the analyte, since the molar absorptivity and the optical path length are fixed with the capillary diameter.

There are two different procedures in which the concentration of the analytes in the sample can be increased prior to their separation by CE: ${ }^{2,3}$ electrophoresis-based methods and chromatography-based methods. Electrophoresis methods ${ }^{4}$ rely on the difference in electrophoretic mobility of the analytes in different zones. Injections can be performed using pressure or voltage. Despite their performance and simplicity, electrophoretic methods suffer because sample volume is limited by the dimensions of 
the capillary. Sample volume limitation can be partially overcome through the use of voltage based injection, but this approach generally suffers from poor reproducibility, discriminates on the basis of ion mobility and is susceptible to small differences in the sample matrix. The main drawback when working with injection procedures is the analysis of complex matrixes, since numerous substances may be concentrated simultaneously with the analytes, causing interferences and loss of efficiency.

By contrast, chromatographic methods ${ }^{5}$ enable higher sample volumes to be injected because the analytes are adsorbed onto a stationary phase. Moreover, the sample clean-up in chromatographic methods is effective because the sample matrix can be removed from the system. Chromatographic-based preconcentration methods ${ }^{6}$ include solid-phase extraction (SPE) and solid-phase microextraction (SPME) ${ }^{7}$, but SPE is the more widely used because it can achieve high concentrations of analyte and is more amenable to polar analytes.

The principle of SPE is similar to that of liquid-liquid extraction (LLE) as it also involves the partitioning of solutes between two phases. However, instead of two immiscible liquid phases, as in LLE, SPE involves partitioning between a liquid (sample matrix) and a solid phase (sorbent). Solid Phase Extraction enables the preconcentration and purification of analytes from solution by sorption on a solid sorbent.

An SPE method always consists of three to four successive steps. ${ }^{5}$ First, the solid sorbent is conditioned using an appropriate solvent, enabling the wetting of the packing material and the solvation of the functional groups in the stationary phase. In addition, it removes possible impurities initially contained in the sorbent or the packaging. The nature of the conditioning solvent depends on the nature of the solid sorbent. The second step is the 
loading of the sample through the solid sorbent. Depending on the system used, volumes can range from $1 \mathrm{ml}$ to 1 liter. The sample flow-rate through the sorbent should be low enough to enable efficient retention of the analytes, and high enough to avoid excessive analysis times. During this step, the analytes are concentrated on the sorbent. Even though matrix components may also be retained by the solid sorbent, some of them pass through, thus enabling some purification of the sample. The third step is the washing of the solid sorbent with an appropriate solvent, having low elution strength, to eliminate matrix components that have been retained by the solid sorbent, without displacing the analytes. The final step consists in the elution of the analytes of interest by an appropriate solvent, without removing retained matrix components. The solvent volume should be adjusted so that quantitative recovery of the analytes is achieved with minimal dilution.

Solid Phase Extraction can solve two main problems in CE analysis; it improves sensitivity and cleans the sample. Solid Phase Extraction has been combined with CE following different approaches; ${ }^{3}$ the simplest is to perform the two procedures separately, i.e. off-line, which is often time-consuming and requires manual handling. In the in-line SPE-CE approach, an SPE cartridge is inserted near the inlet of the separation capillary; the SPE column is an integrated part of the CE capillary and there is no need for modification of the commercial CE instrument. Lack of selective sorbents is certainly the most important weakness of SPE. There is a lot of interest in developing more selective extraction procedures which eliminate the co-extraction of matrix interferences. Such highly selective extractions have been obtained through the use of molecularly 
imprinted synthetic polymers (MIP), restricted access materials (RAMs) and immobilized receptor or antibodies (Immunosorbents).

\section{Immunosorbents:}

Immunosorbents use biological molecules, such as antibodies, and are designed using molecular recognition. As a consequence of the high affinity and selectivity of the antigen-antibody interaction, they permit a high degree of specificity for the analyte.

Immunosorbents enable the concentration of individual compounds or classes of compounds, from liquid matrices in one step and the sample purification of extracts from solid matrices. Immunosorbents are obtained by preparing covalently immobilized or adsorbed antibodies onto a solid support, which is then packed in a cartridge or a column, depending of its use as a chromatographic support or as an extraction media.

\section{Forces involved in antigen-antibody reactions: ${ }^{8}$}

Affinity reactions include a large family of noncovalent binding interactions between molecules that depend on structural relations between the two reactants. The forces governing these interactions are relatively simple and involve the basic forces employed to maintain the conformational structure and integrity of macromolecules. The molecule to be isolated binds to the ligand and is held by a series of forces generated by interactions between the two molecules. The forces that link antigens and antibodies are of four types and their intensity is variable: van der Waals forces are the weakest, of the order of $0.5 \mathrm{kcal} / \mathrm{mole}$ versus 2 to $5 \mathrm{kcal} / \mathrm{mole}$ for electrostatic forces or hydrogen bonds. They are, in any case, of lesser strength than that of covalent forces, which reach 50 to $150 \mathrm{kcal} / \mathrm{mole}$. It is important to note that these forces increase proportionally to the distance between antigen an antibody molecules. They are strongest at shorter distances, 
especially when the two structures are complementary. Increased stability of the antigenantibody combination is seen when the contact area widens. The theoretical distance between antigen and antibodies sites may also be influenced by the flexibility of the antibody molecule, which may allow certain residues to approach closer during contact with the antigen. Van der Waals forces are important bonding forces and are generated by interactions between the electron clouds of the two molecules. These interactions cause a temporary electron disturbance, which causes dipoles to form in both molecules. The two dipoles then set up a series of attractive forces between the molecules. As the displaced electrons swing back through equilibrium, the dipoles oscillate, which generates an attractive force that is inversely proportional to the seventh power of the distance. The coulombic forces that arise from the attraction between two oppositely charged ionic groups are the second most important force. Such groups could be reactive ionized amino $(\mathrm{NH} 3+)$ groups on one molecule attracting ionized carboxyl (COO-) groups on the other. The attractive force created is inversely proportional to the square of the distances between the opposite charges. Ion attractive forces are also known as hydrophobic forces and again results from the close proximity of one molecule to the other. This comingtogether of the molecules forces water from between them, thus reducing the net charge. When two molecules are compatible, they prefer to remain in this low energy state and thus in close proximity to each other. The closeness of the two molecules allows the fourth bonding force, hydrogen bonding. Hydrogen bonding forms when the weak attractive forces formed between hydrophilic groups on the two molecules come into contact and interact. 


\section{Antibodies: ${ }^{9}$}

Antibody molecules are glycoproteins composed of one or more units, each containing four polypeptide chains: two identical heavy chains $(\mathrm{H})$ and two identical light chains (L).The amino terminal ends of the polypeptide chains show considerable variation in amino acid composition and are referred to as the variable (V) region to distinguish them from the relatively constant $(\mathrm{C})$ region. Each $\mathrm{L}$ chain consists of one variable domain $\mathrm{V}$ and one constant domain $\mathrm{C}$. The $\mathrm{H}$ chains consist of a variable domain, $\mathrm{VH}$, and three constant domains $\mathrm{CH} 1, \mathrm{CH} 2$ and $\mathrm{CH} 3$. Each heavy chain has about twice the number of amino acids ( $\mathrm{MW} \sim 50,000$ ) as each light chain ( $\mathrm{MW} \sim 25,000$ ), resulting in a total immunoglobulin of approximately $150,000 .^{31}$

Heavy and light chains are held together by a combination of noncovalent interactions and covalent interchain disulfide bonds, forming bilaterally symmetric structure. The V regions of $\mathrm{H}$ and $\mathrm{L}$ chains comprise the antigen-binding sites of the immunoglobulin (Ig) molecules. Each Ig monomer contains two antigen-binding sites and is said to be bivalent. The hinge region is the area of the $\mathrm{H}$ chains between the first and second $\mathrm{C}$ region domains and is held together by disulfide bonds. ${ }^{31}$

Because compounds of low molecular mass are unable to evoke an immune response, before immunization they have to be modified by bonding to a large carrier molecule, usually a protein such as bovine serum albumin (BSA). ${ }^{10}$ Very often is necessary to introduce a functional group into the selected molecule in order to make this coupling possible. The design of the so-called hapten is still an important variable when trying to obtain antibodies with the required specificity, especially when antibodies are targeted to recognizing a whole class of structurally related compounds. ${ }^{11}$ The functional group that 
is introduced in the antigen molecule should maintain as much as possible the identity of the analyte, but the selection is often determine by trial-and-error assays, once the antibodies have been obtained.

Much effort has been made to develop antibodies that are specific for a compound or a class of structurally related compounds. De Blas et al., ${ }^{12}$ had reported the preparation and evaluation of a monoclonal antibody specific for benzodiazepines. They found that the prepared monoclonal antibodies bind with the highest affinities to benzodiazepines that have a methyl group in position 1 (see fig 1); benzodiazepines that have an electronwithdrawing substituent in position 7 such as $\mathrm{NO}_{2}$ or $\mathrm{Cl}$, also bind with the high affinities while the addition of a $\mathrm{Cl}$ in position 9 or elimination of the carbon ring in position 5 has a negative effect on the affinity for the antibodies. In a similar fashion DelaunayBertocini et al. ${ }^{11,13}$ and Pichon et al. ${ }^{14,15}$ have studied the preparation and cross reactivity of monoclonal and polyclonal antibodies in the selective enrichment of some organic compounds of high interest in environmental applications. The same conclusions apply. Subtle changes in molecular structure can have dramatic effects on affinity. 


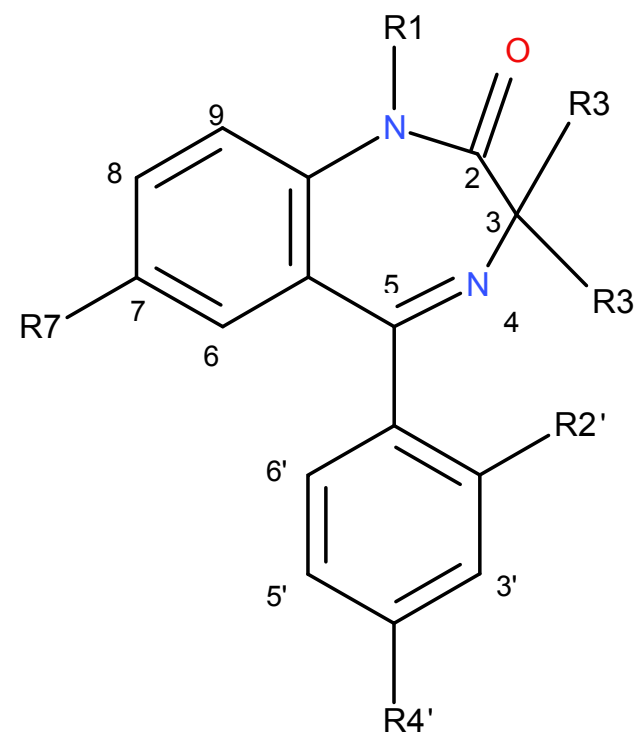

Figure 1 Structure of benzodiazepines 


\section{Solid Support:}

The solid support selected for the immobilization of the antibodies is a critical parameter in the design of the immunosorbent. In addition to basic properties such as chemical and biochemical inertness, good mechanical stability and uniformity in particle size, the solid support should be easily activated to permit antibody attachment, have appropriate pore size to contain the antibodies, and should be hydrophilic in order to avoid any nonspecific interactions. Traditional supports used in high performance immunoaffinity chromatography (HPIAC) and CE; include silica ${ }^{11,13,14,15}$ monolithic silica ${ }^{16}$, synthetic polymers ${ }^{17}$ and magnetic beads. ${ }^{18,19}$

One advantage of using silica in HPIAC is the availability of this support in a form that is both reproducible and that gives good chromatographic efficiency. ${ }^{20}$ Silica particles with diameters of $3-5 \mu \mathrm{m}$ are now commonly used in HPIAC separations because the relatively small particle diameters result in short diffussional distances for solutes, which helps to increase mass transfer and allows for rapid, efficient separations. Although silica particles with diameters of 5-10 $\mu \mathrm{m}$ and pore sizes of $40-100 \AA$ are commonly used in methods such as reversed chromatography, these pore sizes are not appropriate for many proteins ${ }^{20}$ because such pores are comparable in size to the proteins, leading to either the exclusion of proteins from these pores or slow mass transfer as a result of restricted diffusion. Using larger pore sizes also decreases the surface area onto which the ligand can be immobilized. Thus silica supports with intermediate pore sizes in the range of 300-500 $\AA$ are most commonly used with proteins. 


\section{Silica Activation:}

The most common method of preparing silica for antibody immobilization is to silanize the support before coupling the ligand. There are two types of silanization methods: aqueous and non-aqueous. ${ }^{21}$ Available silanes include epoxysilanes, aminosilanes, cyanosilanes, sulfhydrylsilanes, phenyl silanes and glycidoxysilanes, in methoxy, ethoxy, and chloro forms. It is well known that the siloxane bond between the silanol residue and the silane coupling agent is reversible. Monoethoxy-, monomethoxy-, or monochlorosilanes have poor stability on inorganic support materials and are lost rapidly over time. ${ }^{21}$ Trifunctional silanes, on the other hand, produce products that have greater stability. These silanes couple not only to the silanol residue on the support material's surface, but they bind to each other forming a polymer across the surface of the carrier. The heating step after silanization aids in the polymerization reaction by driving off water.

In many cases, after modification with one of the commercially available silanes, chemical modifications are performed to change the functional group for later coupling. Ernst-Cabrera ${ }^{22}$ derivatized silicas of different particle and pore size with three different silanes. These groups were further modified to yield primary hydroxyl functions. The activation of these primary hydroxyl groups with a variety of reagents was studied for the purpose of chemically coupling of proteins. Hage's group from the University of Nebraska has been one of the most prolific groups in the study of activation of silica as a support in High Performance Affinity Chromatography (HPAC). Several studies have been done by this group in order to develop a N-hydroxysuccinimide-activated silica ${ }^{23}$ and evaluate its performance to separate racemic R/S-warfarin. Sulfhydril-reactive 
silica $^{24}$ has been prepared by the same group and evaluated as a support for the immobilization of human serum albumin. The main goal of the study was to compare different methods of support activation (Maleimide-, and iodoacetyl- activated silica) and evaluate the prepared supports based on their retention and ability to separate chiral substances such as D/L-tryptophan, R/S-warfarin and R/S-ibuprofen. Roy ${ }^{25}$ describes the preparation of amino functionalized silica with aminopropyldimethylaminosilane, and its use in the immobilization of chymotrypsin using a glutaraldehyde silica which was obtained by reacting aminopropyl silica with glutaraldehyde.

\section{Antibody Immobilization:}

Antibodies can be immobilized on a solid support in different ways, including physical adsorption, affinity adsorption, and covalent binding. Physical adsorption has been widely used for the coating of microtiter plates in immunoassay technology. Affinity adsorption, using proteins $\mathrm{A}$ or $\mathrm{G}$ immobilized on a stationary phase, permit good orientation of the antibody, but the process suffers from the risk of desorption and steric problems because of the size of the immobilized antibody. Covalent binding appears to be the best process for immobilization as it provides the most stability bond between the solid support and the antibody. When compared to adsorptive immobilization technique, covalent bonding reduces the leakage of antibodies from the solid support during wash and elution steps. There are some common aspects of immobilization processes that strongly influence the antigen-sensing ability of immobilized antibodies. Conformational changes or denaturation during or after immobilization reduce immunosorbent performance. ${ }^{26}$ When antibodies are directly attached to a surface, antigen capture is often interfered by steric hindrances and the limited mobility of the attached antibodies. 
In order to reduce this constraint antibodies are immobilized via a long and a flexible crosslinker. Additionally, the use of a crosslinker reduces the possibility of denaturation caused by the interaction antibody-solid support. Crosslinkers are specialized reagents having reactive groups that will form a bond between two different molecules. Crosslinkers can be divided into three groups: ${ }^{26}$ Zero-length cross-linkers which mediate the conjugation of two molecules by forming a bond containing no additional atom; homobifunctional cross-linkers which are molecules containing the same functional group at both ends that eventually tie two molecules by covalently reacting with the same common groups. These cross-linkers are designed with almost every length and reactivity desired. The third group, the heterobifunctional cross-linkers contain two different reactive groups that can couple to two different functional targets. These heterobifunctional cross-linkers may be selected on their reactivities as well as on the length and type of cross-bridge they posses.

Antibodies contain several types of reactive groups that can be used to form covalent bonds to solid supports. The most frequently used are the amino groups, followed by the sulfhydril, carboxyl, hydroxyl and aromatic groups..$^{26,27,28}$ Some of the methods more commonly used are:

Reductive amination or the Schiff base method ${ }^{10}$ : The procedure generally begins with diol-bonded silica or with epoxy-activated silica that is hydrolyzed to form diol groups. These diol groups are then oxidized by periodic acid to give aldehyde groups, which can react with primary amine groups on a ligand to form a Schiff base, which further can be stabilized through the use of sodium borohydride. 
Glutaraldehyde based methods ${ }^{25,29}$ : Using this method, silica containing amine groups are reacted with a dialdehyde (e.g., glutaraldehyde) to produce aldehyde activated silica. The activated silica is then reacted with a ligand that contains primary amines, forming a Schiff base that is later reduced.

Carbonyldiimidazole (CDI) based methods ${ }^{28}$ : This process often begins with diol-bonded silica. These groups are reacted with 1,1 '-CDI to give imidazolylcarbamate-activated silica, which is later reacted with a primary amine on a ligand to form a stable bond between the ligand and the support.

N-hydrosuccinimide (NHS) method ${ }^{23}$ : This process begins with hydroxyl or amine groups on the support, which can be reacted with reagents like disuccinimidyl glutamate, disuccinimidyl subarate or disuccinimidyl carbonate to form the linkage ligand-support. Maleimide method ${ }^{24}$ : This method is used for ligands with Sulfhydril groups. In this technique, amine-derivatized silica is reacted with a homobifunctional or heterobifunctional crosslinking reagent containing at least one maleimide group. The maleimido-activated support can then be reacted with a Sulfhydril-containing ligand for its immobilization.

Hydrazine method 11,13,14,15: The carbohydrate moiety found on the Fc portion of antibodies has become a favored site for antibody immobilization. This is performed by simply oxidizing the antibody's carbohydrate vicinal hydroxyl group with sodium periodate to form a reactive aldehyde function. The aldehyde is then linked to silica containing hydrazine, to form stable covalent hydrazine bonds. 


\section{Applications of immunosorbents:}

Wieboldt et al. ${ }^{30}$, describes the use of a benzodiazepine-specific antibody for screening small-molecule libraries by immunoaffinity ultrafiltration. The relation between antibody concentration and extraction efficiency was studied, and it was found that larger amounts of antibody yield LC/MS chromatograms with improved signal-to-noise ratios. The correlation between the amount of antibody and signal level, where the amount of antibody is the limiting reagent and there is a constant and excess concentration of benzodiazepine, can be explained by the fact that there are more available sites for binding, resulting in a greater amount of eluted benzodiazepine. According to the authors, the procedure demonstrated that the molecular recognition property of the antibody for mixtures of related compounds can be used to develop a better understanding of the role molecular structure plays in antibody recognition

Choi J. et al. ${ }^{31}$ developed an immunoassay for the detection of methamphetamine in urine by capillary electrophoresis (CE) with laser induced fluorescence (LIF). In this work the methamphetamine was labeled with fluorescein isothiocyanate (FITC) to compete with free methamphetamine in the sample for the antibody binding. The detection limit reported was $19.0 \mathrm{ng} / \mathrm{ml}$. Morphine and related compounds were detected in urine using a multi-target antibody prepared by conjugation of morphine to BSA. ${ }^{32}$ The analytes were separated by capillary electrophoresis and monitored at $214 \mathrm{~nm}$. Recovery and limit of detection were $91-105 \%$ and $10-20 \mathrm{ng} / \mathrm{ml}$ respectively.

Flunitrazepam and its metabolites in urine have been analyzed by Deinl and colleagues. ${ }^{33}$ The procedure uses on a column-switching technique which used an immobilized antibody in an extraction column following concentration on a column filled with $5 \mu \mathrm{m}$ 
particles of LiChrospher 60 RP-select B precolumn, and separation on a LiChrospher 60 RP-select B. The limit of detection reported was $2 \mathrm{ng} / \mathrm{ml}$ in urine using UV-VIS detection at $254 \mathrm{~nm}$.

Immunoaffinity solid phase microextration probes have been developed by Lord et al., ${ }^{7}$ for the analysis of 7-aminoflunitrazepam in urine. The drug was extracted by immobilized antibodies and analyzed by LC-MS/MS. The developed method had a limit of detection of $0.02 \mathrm{ng} / \mathrm{ml}$, with accuracy ranging from $1 \%$ to $27 \%$ and precision ranging from $2 \%$ to $10 \%$ between the lower and upper limits of quantitation. In further research by the same group, ${ }^{34}$ immunoaffinity solid phase microextraction probes were developed with antibodies specific for benzodiazepines. The limits of detection were 0.001-0.015 $\mathrm{ng} / \mathrm{ml}$ depending on the antibody, and the dynamic range extended from $0.2-2 \mathrm{ng} / \mathrm{ml}$.

In the environmental field a lot of research has been done to develop immunosorbents for analysis of tryclopyr ${ }^{55}$, isopruturon ${ }^{13}$, triazines ${ }^{11}$, propanil ${ }^{14}$, and phenylurea ${ }^{15}$, among others.

Overall, sensitivity in CE can be improved by using immunosorbent solid phase extraction (IS-SPE). Coupling of SPE with immunosorbent improves the selectivity of the sorbent. These coupled techniques (IS-SPE-CE) provide an excellent application for the analysis of trace drugs in complex matrices.

Because of its abundance in proteins and its reactivity, amino groups are the most frequently functional groups used for attachment of antibodies to the solid support. In order to improve the antibody orientation it is recommended to use a crosslinker, which provides functional groups that can be easily activated, minimize the steric hindrance, 
improve mobility of the attached antibody, and reduce the possibility of denaturation caused by the interaction solid support-antibody.

The preferred method for preparing immunosorbents is covalent binding of the antibody to the solid support due to the stability of the formed bond.

The goal of this research is to prepare an immunosorbent by coupling an amino functionalized silica support with a benzodiazepine-specific antibody; using SMCC and 2-iminothiolane as amino-reactive crosslinkers. 


\section{Chapter II: Immunosorbent Preparation}

\section{Introduction:}

The immobilization of biomolecules to solid materials is a frequently used procedure to confer a specific affinity activity to the surface. The goal is to attach the fragile ligand in such a way as to leave it structurally intact with its active sites easily accessible for specific binding to analytes present in the surrounding fluid phase. The solid support selected for covalent immobilization of antibodies is of vital importance when designing immunosorbents. Silica, a mechanically stable support which is chemically and biologically inert, and easily activated can be chosen with a specific pore sizes that made silica useful in the determination and immobilization of large molecules. Commercial silica with different chemical functionalities is now available, making this substrate easily activated with wide variety of cross linkers. A very broad classes of chemical groups can thus be accessed using this support.

Determination of the surface solid-supported functional groups is very important from the point of view of characterizing the raw material, selecting the appropriate solid support, and in optimizing the coupling conditions of ligands. Amino groups on solid supports can be quantified by the use of 2,4,6-trinitrobenzene sulfonic acid (TNBS) ${ }^{36}$, ophthaldialdehyde (OPA) ${ }^{37}$, and by the well- known Ellman's reagent. ${ }^{38,39}$

When antibodies are used as immobilized biomolecules, they should be immobilized in high concentration on the support, and in the proper orientation to produce the highest possible capture of the binding analyte. It is best to use the purest antibody in order to obtain an immunosorbent with the highest capacity to bind the target compound. The use of unpurified antibodies can result in immunosorbents with low binding capacity due to 
the fact that impurities will also bind the support, affecting the performance. There are different schemes for antibody purification ${ }^{9}$ but the most important variable to be taken in account when developing a purification strategy is the antibody class (IgG, $\operatorname{IgM}, \operatorname{IgA}$, $\operatorname{IgD}, \mathrm{IgE})$. Oriented immobilization of antibodies is a very important issue in optimizing antigen detection on solid surfaces. Properly oriented antibodies, with their antigen binding sites well exposed to the solution phase, exhibit higher antigen binding capacities when compared to randomly oriented antibodies. Most conjugation procedures involve coupling antibodies to solid support via the $\varepsilon$-amino groups of their lysine residues, which are the second most abundant functional group present in proteins ${ }^{40}$. Although this conjugation procedure results in a random attachment with some probability of forming improperly oriented antibodies, the use of a cross linker (2-iminothiolane) improves the orientation and avoids the steric interference with the solid support. ${ }^{41}$ The reagent 2iminothiolane reacts with amino groups in a ring-opening reaction resulting in a permanent modification that contains terminal sulfhydril residues. ${ }^{26,42}$

In this section silica and the benzodiazepine-specific antibody will be characterized, in order to evaluate their main characteristics from the point of view of immobilization. After characterization, the immunosorbent will be prepared by reaction of the amino silica and the antibody that have been previously activated with the crosslinkers SMCC and 2-Iminothiolane respectively.

\section{Materials and methods}

\section{Chemicals}

2,4,6- trinitrobenzene sulfonic acid (TNBS), sodium tetraborate, glycine, methanol, Sodium Phosphate, dimethyl formamide (DMF), succinimidyl 4-(N-maleidomethyl)- 
cyclohexane -1-carboxilate (SMCC), 4-dimethyl-aminopyridine (DMAP), Lowry test kit, sodium bicarbonate, sodium dodecyl sulfate, $\mathrm{HCl}$, Gradiant gels (8-15\%), with Coomassie brilliant blue, dialysis tubing, DEAE, 2-iminothiolane (2-It), Millipore Ultracel YM-10 (NMWL= 30,000) Microcon centrifugal filter device, EDTA, antibody specific for flunitrazepam (Biogenesis 4510-0004 Flunitrazepam: antibody, sheep. serum),

\section{Instrumentation}

Analyses of protein as well as determination of amino groups were performed on a UVVisible Varian Cary 100 Bio.

\section{Silica characterization:}

The characterization of the amino silica was done by the 2,4,6- trinitrobenzene sulfonic acid (TNBS) method ${ }^{36}$ (Fig 2). Briefly 0.2 gram of amino silica was reacted with $1.0 \mathrm{ml}$ of $0.01 \mathrm{M}$ TNBS in $9.0 \mathrm{ml}$ of $0.1 \mathrm{M}$ sodium tetraborate. A reference sample composed of $9.0 \mathrm{ml}$ of $0.1 \mathrm{M}$ sodium tetraborate and $1.0 \mathrm{ml}$ of $0.01 \mathrm{M}$ TNBS was prepared. After $2 \mathrm{~h}$ at $37^{\circ} \mathrm{C}$ the silica was sedimented and $1.0 \mathrm{ml}$ of the supernatant solution was diluted with $5.0 \mathrm{ml}$ of $0.1 \mathrm{M}$ sodium tetraborate, and $0.5 \mathrm{ml}$ of $0.03 \mathrm{M}$ glycine. A blank sample was prepared in the same way but $0.5 \mathrm{ml}$ of water was added instead of glycine. After $25 \mathrm{~min}$ at $25^{\circ} \mathrm{C} 10 \mathrm{ml}$ of cold methanol was added and the absorbance of the sample was read against its own blank at $340 \mathrm{~nm}$. The concentration of the amino groups was determined from the difference between the absorbance of reference and sample, using a molar absorption coefficient of $12400{ }^{36}$ 


\section{Silica Activation:}

Amino silica was activated by the procedure described by Mallik, et al. ${ }^{24}$ (Fig 3). Briefly, $17 \mathrm{mg}$ of amino silica was reacted for $21 \mathrm{~h}$ at room temperature with $400 \mu \mathrm{l}$ of dimethyl formamide (DMF) which contains $13 \mu \mathrm{M}$ of succinimidyl 4-(N-maleidomethyl)cyclohexane -1-carboxylate (SMCC) and $4 \mu \mathrm{M}$ of 4-dimethyl-aminopyridine (DMAP). The resulting maleimide-activated silica was washed several times with DMF. Prior to immobilization the activated silica was washed three times with $0.1 \mathrm{M}$ phosphate buffer pH 7.2

\section{Antibody Characterization:}

The concentration of the antibody was determined by the Lowry method ${ }^{43}$, purity and structure was determined by SDS PAGE electrophoresis ${ }^{44}$, and total amino groups by the method proposed by Hermanson. ${ }^{26}$

The Lowry method was performed using a kit obtained from Thermo Scientific Pierce. Briefly the method ${ }^{43}$ consists of a ten minutes sample or standard incubation with one $\mathrm{ml}$ of Modified Lowry Reagent. Exactly at the end of the incubation time, $100 \mu \mathrm{L}$ of $1 \mathrm{X}$ Folin-Ciocalteu Reagent was added and incubated for $30 \mathrm{~min}$. At the end of the incubation period the sample or standard is read at $750 \mathrm{~nm}$. A calibration curve was constructed using a $1 \mathrm{mg} / \mathrm{ml} \mathrm{BSA} \mathrm{solution} \mathrm{(Fig.} \mathrm{4).}$

To quantify the amino groups in the antibody ${ }^{26}, 100 \mu \mathrm{g}$ of antibody was incubated for 2 h at $37 \mathrm{C}$ with $0.5 \mathrm{ml}$ of $0.01 \%(\mathrm{w} / \mathrm{v})$ TNBS prepared in $0.1 \mathrm{M}$ sodium bicarbonate. After incubation, $0.5 \mathrm{ml}$ of $10 \%$ sodium dodecyl sulfate and $0.25 \mathrm{ml}$ of $1 \mathrm{~N} \mathrm{HCl}$ were added. The absorbance of the solution was measured at $335 \mathrm{~nm}$ and the number of amino 
group present was calculated by comparison to a standard curve prepared (Fig. 5) using glycine as a standard.

Purity and structure were measured by SDS-PAGE performed using Phast system (Amersham Pharmacia Biotech) apparatus, following the standard procedure. Gradiant gels (8-15\%) were used. Gels were stained with Coomassie brilliant blue. After the gel was developed (Fig 6) Rf values for the antibody, and the standard were calculated and a graph (Fig. 7) was constructed. 


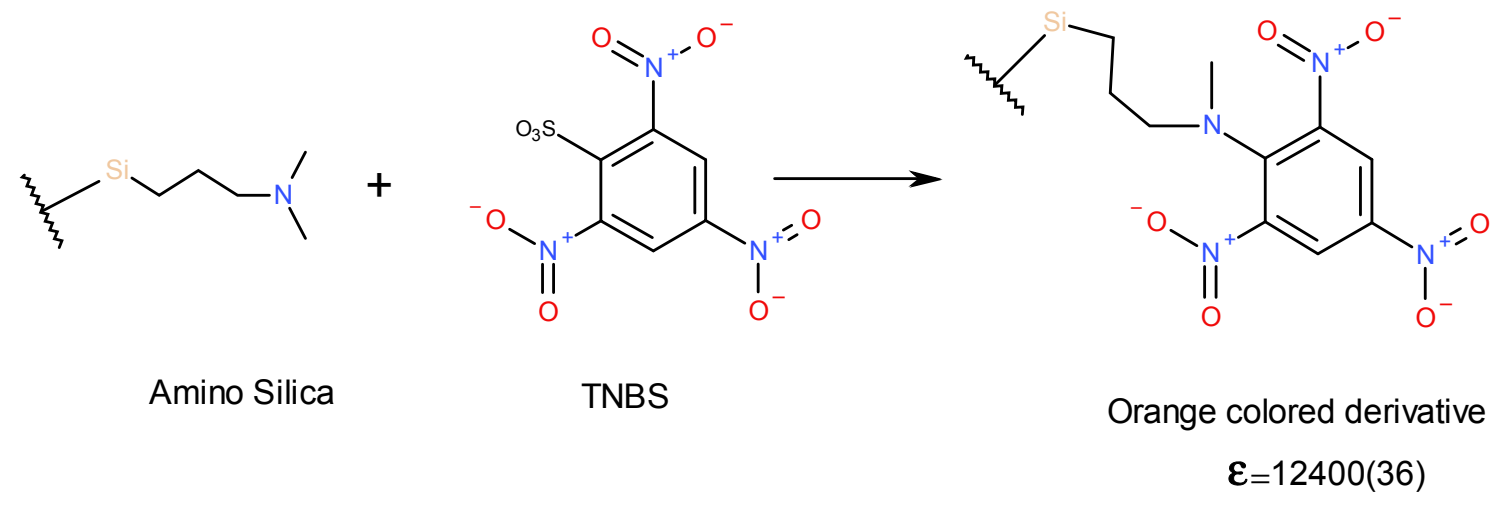

Figure 2. Reaction of amino groups with trinitro benzenesulfonic acid (TNBS) 


\section{Antibody Purification:}

The antibody was purified according to the method proposed by Harlow and Lane ${ }^{9}$ Briefly, $10 \mathrm{mg}$ of crude antibody were incubated with $3 \mathrm{~mL}$ of $4 \mathrm{M}$ ammonium sulfate overnight at $4^{\circ} \mathrm{C}$. Then the mixture was centrifuged at $3000 \mathrm{~g}$ for $30 \mathrm{~min}$, the supernatant was removed and the pellet was resuspended in $1 \mathrm{~mL}$ of $5 \mathrm{mM}$ sodium phosphate. The resuspended material was dialyzed against three changes of $5 \mathrm{mM}$ sodium phosphate $\mathrm{pH}$ 6.5. Once dialyzed the solution remaining in the dialysis bag was mixed with $5 \mathrm{~mL}$ of DEAE resin and incubated for 1 hour at room temperature. Then the DEAE resin was removed by passing the slurry through a filter.

\section{Antibody Activation:}

The antibody was activated according to the procedure developed by Gupta ${ }^{45}$ (Fig. 8). Briefly, $0.17 \mathrm{mg}$ of antibody was incubated at room temperature with $0.8 \mu \mathrm{lof}$ a $2 \mathrm{mg} / \mathrm{ml}$ solution of 2-iminothiolane (2-It) prepared in sodium phosphate buffer $\mathrm{pH}$ 7.2. After 1.5 $\mathrm{h}$ of incubation the solution was transferred into an Millipore Ultracel YM-10 (NMWL= 30,000) Microcon centrifugal filter device, centrifuged at $1000 \mathrm{~g}$ for $10 \mathrm{~min}$, and washed three times with $0.1 \mathrm{M}$ phosphate buffer $\mathrm{pH} 7.2$ containing $1 \mathrm{mM}$ EDTA. 


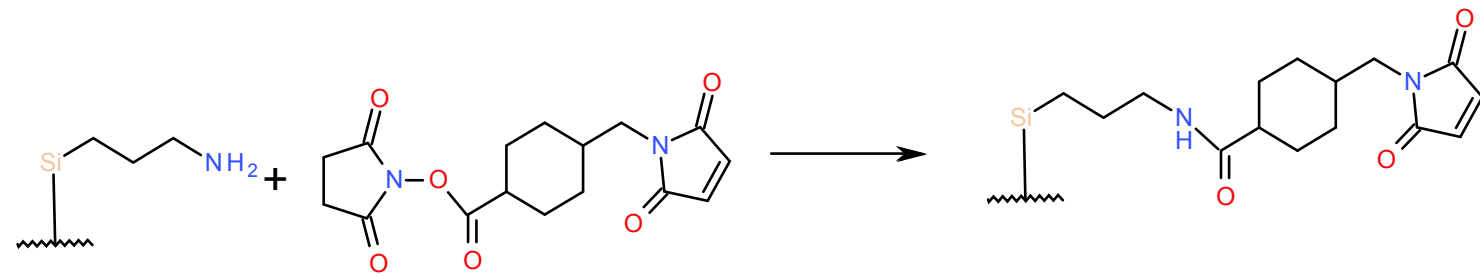

aminopropyl silica

SMCC

Activated amino propyl silica

Figure 3. Silica activation with SMCC. Amino silica was activated by the procedure described by Mallik, et al. ${ }^{24}$ Briefly, $17 \mathrm{mg}$ of amino silica was reacted for $21 \mathrm{~h}$ at room temperature with $400 \mu \mathrm{l}$ of dimethyl formamide (DMF) which contains $13 \mu \mathrm{M}$ of succinimidyl 4-(N-maleidomethyl)-cyclohexane -1-carboxilate (SMCC) and $4 \mu \mathrm{M}$ of 4dimethyl-aminopyridine (DMAP). 


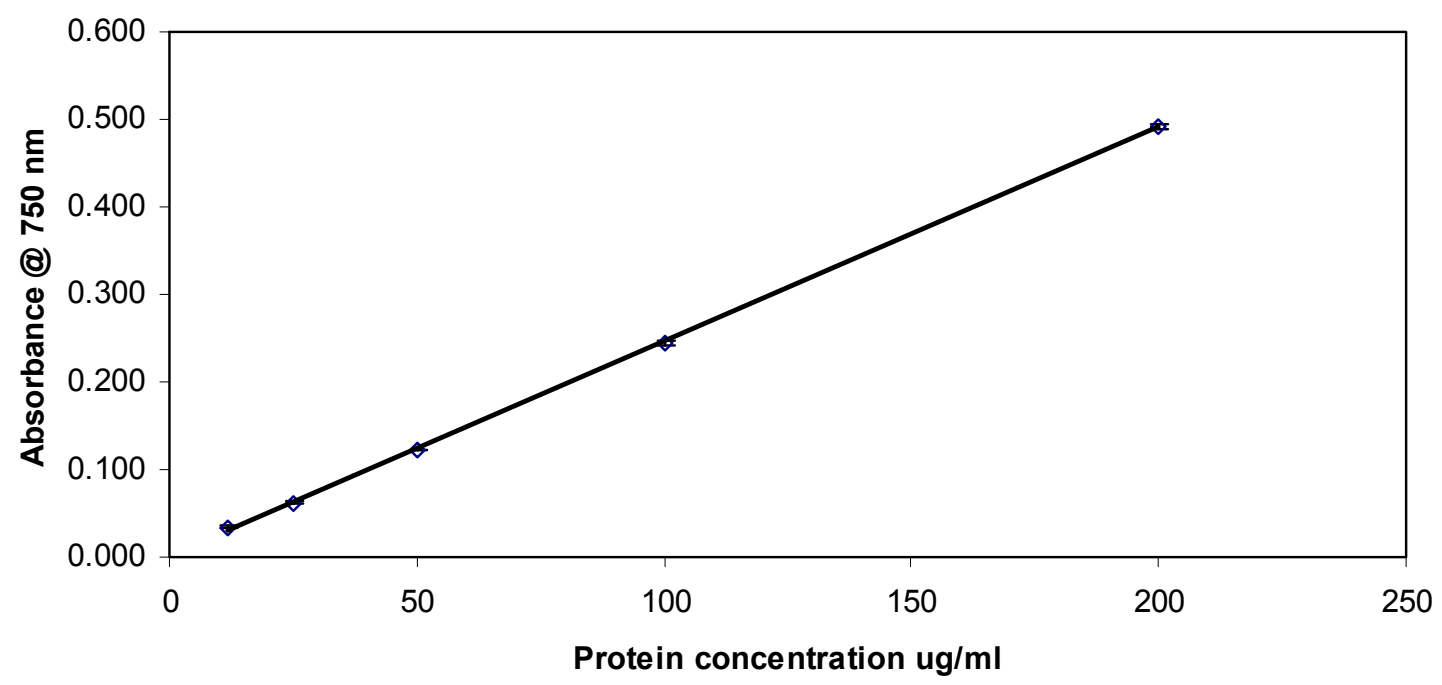

Figure 4. Linear regression analysis for protein determination in the range from 12 to 200 $\mu \mathrm{g} / \mathrm{ml}$. Standard samples were prepared from a $1 \mathrm{mg} / \mathrm{ml}$ bovine serum albumin. One $\mathrm{ml}$ of the corresponding standard was mixed with one $\mathrm{ml}$ of modified Lowry reagent, incubated for $10 \mathrm{~min}$., followed by the addition of $100 \mu \mathrm{l}$ of Folin-Ciocalteu reagent and incubated for $30 \mathrm{~min}$. (All the reagents used are part of a kit from Thermo Scientific). Standards as well as samples were read a $750 \mathrm{~nm}$. The corresponding equation is $\mathrm{y}=$ $0.0017+0.0024 \mathrm{x}$ with a coefficient of correlation $\mathrm{r}^{2}=0.9999$. The error bars represent a range of \pm 1 standard deviation. 


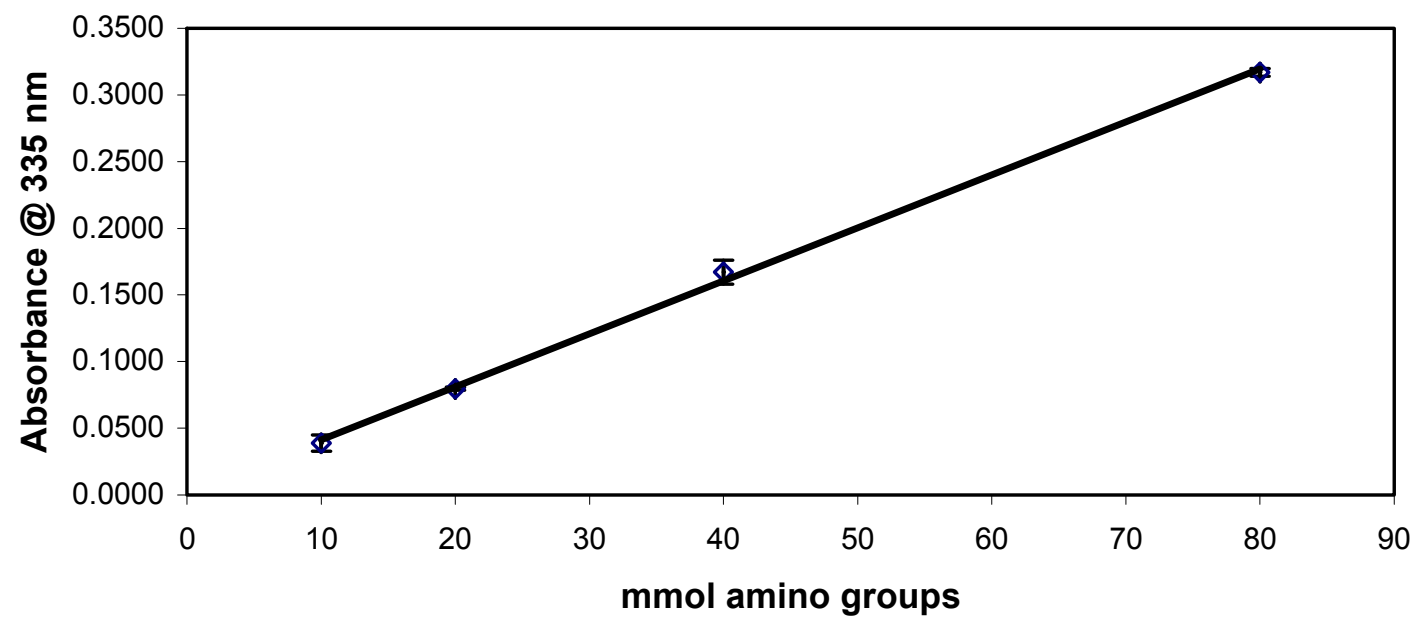

Figure 5. Linear regression for analysis of amino groups on proteins in the range from 10 to $80 \mathrm{mmol}$ of amino groups. Glycine $99 \%$ purity was used as a standard. Standard samples were prepared in $0.1 \mathrm{M}$ sodium bicarbonate, $\mathrm{pH} 8.5$. One $\mathrm{ml}$ of the corresponding standard was mixed with $0.5 \mathrm{ml}$ of $0.01 \%(\mathrm{w} / \mathrm{v})$ TNBS (prepared in $0.1 \mathrm{M}$ sodium bicarbonate, $\mathrm{pH} 8.5$ ) and incubated for $2 \mathrm{~h}$. at $37^{\circ} \mathrm{C}$. After this period of time standards were mixed with $0.5 \mathrm{ml}$ of $10 \%$ sodium dodecyl sulfate and $0.25 \mathrm{ml}$ of $1 \mathrm{~N} \mathrm{HCl}$ and read at $335 \mathrm{~nm}$. The corresponding equation is $\mathrm{y}=0.0016+0.0040 \mathrm{x}$ with a coefficient of correlation $\mathrm{r}^{2}=0.9994$. The error bars represent a range of \pm 1 standard deviation. 

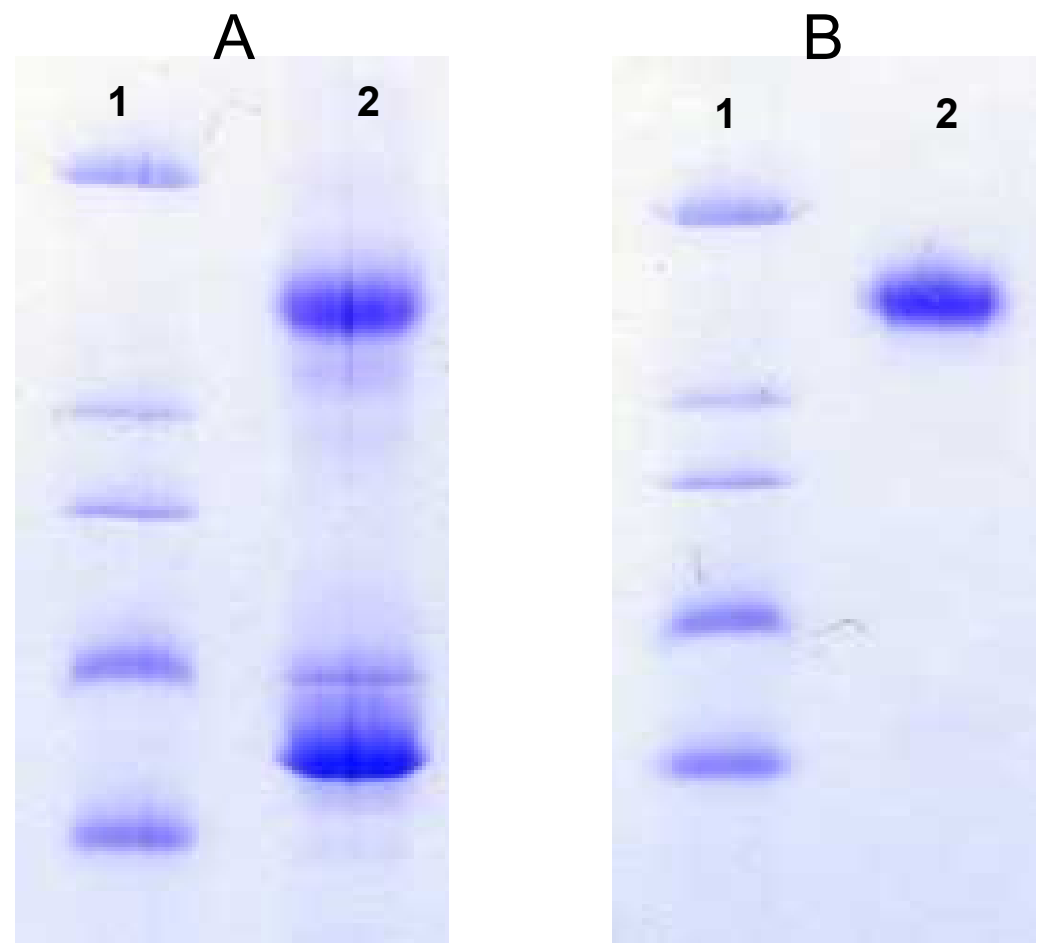

Figure 6. Determination of purity in crude antibody by SDS-PAGE. A. Unpurified antibody. Total protein/lane $=3 \mu \mathrm{g}$. From left to right: Lane 1, standard proteins (from top to bottom: Myosin (200000 Da), B-galactosidase (116250 Da), Phosphorilase B (97400 Da), Serum Albumin (66200 Da), Ovalbumin (45000 Da). Lane 2, unpurified flunitrazepam specific antibody. B. Purified antibody. Total protein/lane $=3 \mu \mathrm{g}$. From left to right: Lane 1, standard proteins (same standard as lane 1 in graph A). Lane 2, Purified flunitrazepam specific antibody. 


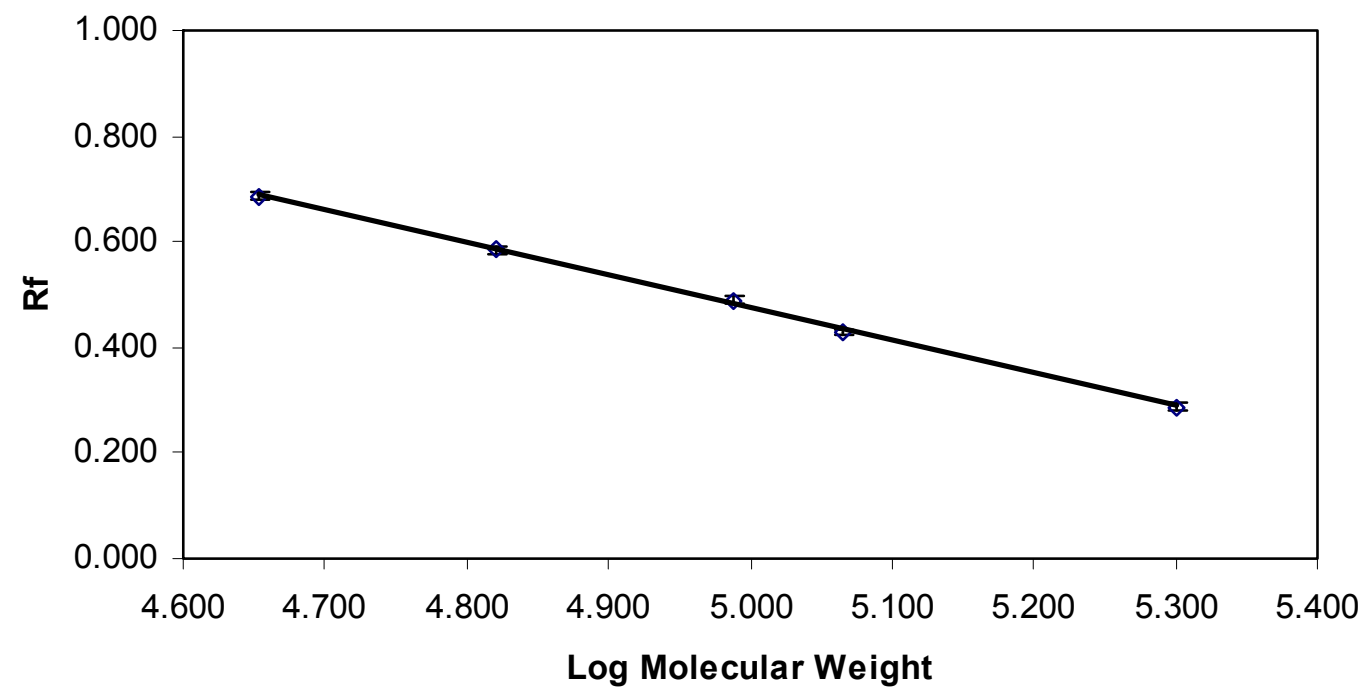

Figure 7 Calibration curve for $\log _{10}$ of molecular mass against $\mathrm{Rf}$ (mobility relative to the tracking dye) by SDS-PAGE. The identities of the proteins used, together with their molecular masses, are given in graph 7 . The corresponding equation is $\mathrm{y}=3.557-$ $0.6164 x$ with a coefficient of correlation $r^{2}=0.9994$. The error bars represent a range of \pm 1 standard deviation. 


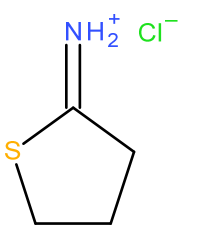

$+$

$\mathrm{Ab}-\mathrm{NH}_{2}$

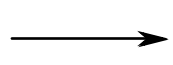

2-Iminothiolane

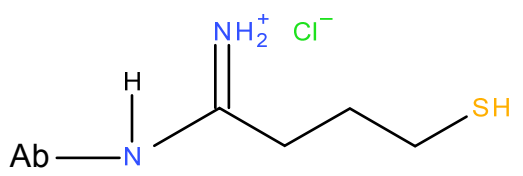

Sulfhydryl activated antibody

Figure 8. Antibody activation with 2-iminothiolane. The antibody was activated according to the procedure developed by Gupta ${ }^{45}$. Briefly, $0.17 \mathrm{mg}$ of antibody was incubated at room temperature with $0.8 \mu \mathrm{l}$ of a $2 \mathrm{mg} / \mathrm{ml}$ solution of 2-iminothiolane (2-It) prepared in sodium phosphate buffer $\mathrm{pH}$ 7.2. 
<smiles>CC(C)SCCCNC(=O)C1CCC(CN2C(=O)C=CC2=O)CC1</smiles>

Activated aminopropyl silica

sulfhydryl activated antibody

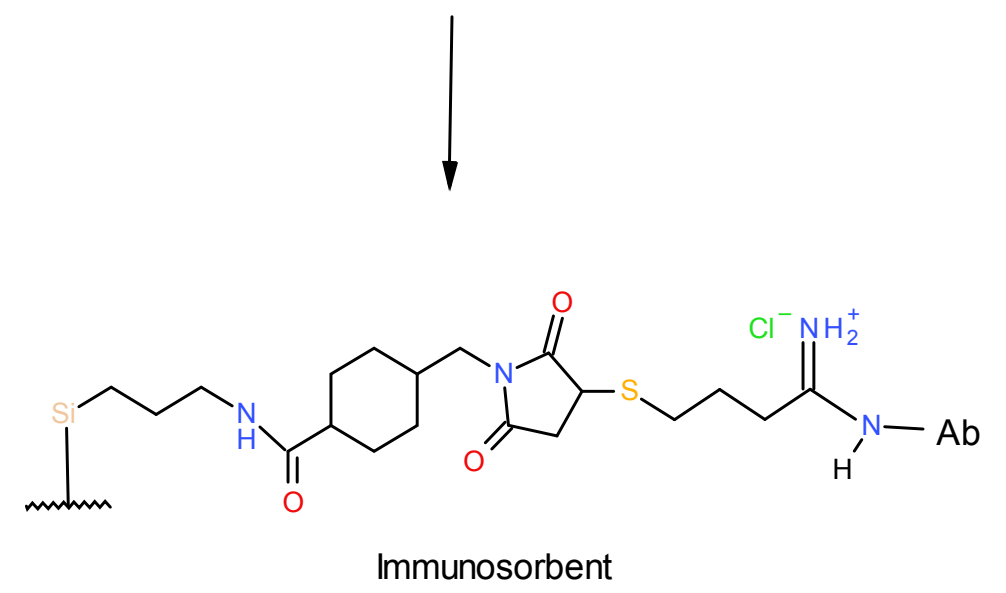

Figure 9 Antibody-silica attachment. Attachment of the antibody to the maleimideactivated silica was done following the procedure developed for Gupta ${ }^{45}$ for conjugation of antibodies to enzymes. Briefly, $10 \mathrm{mg}$ of the activated maleimide-activated silica was incubated at room temperature with the previously activated antibody $(170 \mu \mathrm{g})$. After $2 \mathrm{~h}$ the silica-antibody immunosorbent, (IS) was separated decanted by centrifugation. 


\section{Attachment of the antibody to silica:}

Attachment of the antibody to the maleimide-activated silica followed the procedure developed by Gupta ${ }^{45}$ for conjugation of antibodies to enzymes (Fig. 9). Briefly, $10 \mathrm{mg}$ of the activated maleimide-activated silica was incubated at room temperature with the previously activated antibody $(170 \mu \mathrm{g})$. After $2 \mathrm{~h}$ the silica-antibody immunosorbent, (IS) was separated decanted by centrifugation. Three additional washes were done using $0.1 \mathrm{M}$ phosphate buffer. After the third wash the immunosorbent was reconstituted with $100 \mu 1$ of $0.1 \mathrm{M}$ phosphate buffer and stored to 2-8 C.

\section{Results and Discussion:}

The solid support selected for covalent immobilization of antibodies should be chemically and biologically inert easily activated and mechanically stable. In my study silica modified with aminopropyl groups has been chosen because this support meets almost all the requirements for a good support. In particular its pore size of $300 \AA$ is optimal for making the aminosilica accessible to large antibodies molecules or analytes.

For a correct use of a support containing amino groups, a quantitative analysis of the number of active amino groups is required. There are several methods reported in the literature to do this, Some of them measured the number of total amino groups, others the number of reactive amino groups. From the point of view of silica functionalization our interest was to measure the amino groups available for conjugation, that is why $2,4,6$ trinitrobenzenesulfonic acid (TNBS) was chosen as the method to quantify amino groups on silica. The value obtained was $42 \mu \mathrm{mol}$ of available amino group/ gram of silica. In

the work done by Mallik, et. al. ${ }^{24}$ the total amino groups reported for the same amino silica was $328( \pm 7) \mu \mathrm{mol}$ of amino groups per gram of silica, and of them only $4.4 \%$ 
could be activated. Based on this value $(328 \pm 7 \mu \mathrm{mol})$, the amount of amino groups determined for the TNBS method was $13 \%$ of the total amino groups present in the silica sample, a result that is with good agreement with the $4.4 \%$ of activation found for Mallik and colleagues. ${ }^{24}$

The silica activation was carried out using the procedure proposed by Mallik et al. ${ }^{24} \mathrm{On}$ the basis of the amount of reactive amino groups on amino silica the SMCC used was 18 mol SMCC per mol of amino group. The high ratio was used to guarantee that all the amino groups were activated. On the basis of the total amino groups reported by Mallik, the ratio was $2.3 \mathrm{~mol} \mathrm{SMCC} /$ per mol amino group, which was three times the ratio assayed by Mallik (0.57-0.67). Therefore a higher ratio was chosen in order to improve the silica activation. Mallik reported that the lower ratio $(0.57-0.67$, on the basis of the total amino groups) was one of the reasons they believed had resulted in a low activation numbers for the support.

The concentration of the antibody (Biogenesis 4510-0004 Flunitrazepam: antibody, sheep. serum) determined by the Lowry method was $9.4 \mathrm{mg} / \mathrm{ml}$, which represents a too high value for a commercial product seemed to indicate that an unpurified antibody had been used. The Lowry method was used to quantify the protein content in the antibody as received. When a quick protein determination was required the quantification of protein was done by converting absorption measurements at $280 \mathrm{~nm}$ according to a conversion factor of 1.42 absorbance units $\mathrm{mg}^{-1} \mathrm{~mL}^{-1}$ in a one-centimeter cuvette ${ }^{46}$.

From the non-reduced SDS PAGE electrophoresis two peaks can be seen (Fig. 6), which correspond to 153000 Daltons (D) and 64000 Daltons, showing that the antibody is not pure which also explains the high total protein value obtained using the Lowry test. From 
the molecular weight of the contaminant (Fig 7) it can be postulated that albumin $(\mathrm{MW}=67000)$ is the contaminant.

When performing antibody immobilizations one of the main requirements is to have a purified antibody, which can eliminate the potential attachment of unreactive species into the solid support, decreasing the amount of binding reactive species. The purification of antibodies is one of the most critical steps in the whole process of antibody production. Its success depends on many factors, the most critical issue that must be taken in account is the antibody class (IgG, $\operatorname{IgM}, \operatorname{IgE}, \operatorname{IgA}$ and $\operatorname{IgD}){ }^{9}$. Depending of the class, different routes could be chosen for purification. The first purification step involved precipitation with ammonium sulfate. Precipitation is based on the fact that most globular proteins display lower solubility at high salt concentrations, due to the fact that when high concentrations of charged ions are added to proteins in solution, these groups compete with proteins for binding to water, removing the water molecules from protein decreasing their solubility. Because the resulting antibody could be contaminated with other highmolecular weight proteins as well as proteins that are trapped in the precipitate, an additional purification is required. Ion-exchange purification using DEAE was chosen as a second purification step. Purification by ion-exchange is based on the fact that antibodies have a more basic isoelectric point than the majority of other serum proteins. During this purification step, the $\mathrm{pH}$ and the salt conditions of the antibody solution were adjusted so that the antibody did not bind to the matrix. Prior to the ion-exchange separation to remove unwanted low molecular weight solute from the sample, a conventional dialysis step was performed. After purification a PAGE-SDS test was done and only one peak could be seen (Fig. 6), which corresponded to 153 KDalton (KD). The 
fact that only one peak was present demonstrated that the purification process was effective for this class of antibody, and that the antibody molecular weigh was approximately 153 KDalton.

Once a purified antibody was available the main concern was how many groups were available for modification. Because the antibody modification will be done through its amino groups, a characterization of the amount of "available" lysine (lysine residue in which the $\varepsilon$-amino group is free) is of primary importance. To do this a method using TNBS ${ }^{26,47}$ was chosen because to its specific reaction with primary amino groups ${ }^{48}$.

The number of amino groups on the purified antibody was calculated based on a calibration curve performed using glycine as a standard (Fig 5). In order to evaluate the method BSA was run as a control. The value obtained from the BSA sample was $66 \mathrm{~mol}$ of amino groups per mol of BSA. This value was in very good agreement with the value reported in reference ${ }^{49}$ (59 lysine residues, $30-35$ of which are capable of reacting). The value obtained for the antibody was 76 mol of amino group per mol of antibody.

Heterobifunctional crosslinking agents can be used to control the degree of protein conjugation, limiting polymerization and controlling the molar ratio of each component in the final complex. In this study SMCC and 2-iminothiolane (2-IT) were chosen because their reactivity occurs through the amino groups. SMCC is a water-insoluble, stable compound which can be reacted under anhydrous conditions to the amino groups on the silica matrix decreasing the possibility of silica hydrolysis. In order to improve the attachment an alkylating catalyst (DMAP) was chosen. The NHS ester end of the SMCC, reacts with the primary amino group on the aminopropyl silica to form stable amide bond, and leave at the other end of the molecule a sulfhydryl reactive group (Fig. 3) ${ }^{26}$ On 
the other hand, because of its solubility in water and its reactivity through amino groups, 2-IT is an appropriate reagent for activation of proteins. The reagent 2-IT is used to incorporate thiol groups into proteins by reactions of their lysine amino groups. 2-IT is a cyclic imidothioester that react with primary amines in a ring opening reaction (Fig. 8) that generates a free sulfhydryl. ${ }^{26}$

As mentioned earlier, antibody activation was performed using the $\varepsilon$ amino groups of lysine groups, following a procedure developed by Gupta. ${ }^{39}$ Hermanson, ${ }^{26}$ who performed the same antibody activation, suggested a molar ratio of $1.6 \mathrm{~mol}$ of 2iminothiolane per mol of antibody. Considering that the available amino groups are 76 mol per mol of antibody, a ratio of 48 moles of amino groups per mol of 2-iminothiolane was assayed. With this low ratio a low multi-site attachment occurred, which improved the IS performance from the point of view of antibody orientation.

The coupling reaction between the activated amino silica and the activated antibody (Fig. 9) was carried out at a ratio of $59 \mathrm{mg}$ of activated silica/ $\mathrm{mg}$ of antibody. If all the available amino groups has been activated, the amount of SMCC groups available for binding are $42 \mu \mathrm{mol}$ SMCC groups/g silica i.e. $0.42 \mu \mathrm{mol}$ of SMCC groups are available to react with $1 \mathrm{nmol}$ on antibody. This ratio was chosen in order to promote the complete antibody binding to the silica activated support. The fact that the antibody has a low activation ratio (1.6 mol of 2-iminothiolane per mol of antibody) minimizes the potential for multi site attachment that could occur with a highly activated support, reacting with a highly activated antibody.

As a result of the above experiments, the amount of amino groups on the silica, and on

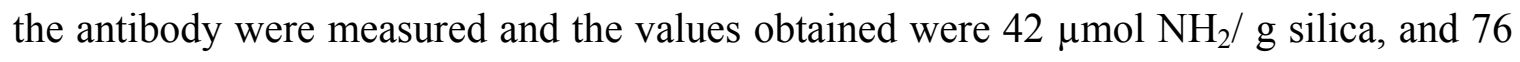


mol $\mathrm{NH}_{2} /$ mol of antibody. Based on the amount of amino groups on the antibody, a ratio of amino groups to 2-iminothiolane was chosen, which guarantee a low antibody activation. This low activation generates an antibody with few sites available to react with the solid support reducing the potential for multi-site attachment. Furthermore a high ratio of silica/SMCC was chosen in order to produce a highly activated support which binds to the greatest possible amount of antibody.

The purity of the antibody is the main concern when preparing immunosorbents, owing to the fact that impurities can be attached to the solid support decreasing the available places for antibody binding, and increasing the probability of non-specific binding. From the results of the SDS-PAGE test, it can be seen that the purification procedure developed has been effective producing an antibody free of contaminants. 


\section{Chapter III: Performance evaluation}

\section{Introduction:}

The coupling of electrophoretic methods with mass spectrometric detection procedures produces a powerful tool for separation and detection of small amounts of unknown samples. Electrospray ionization (ESI) is frequently the method of choice for CE/MS because of its versatility and sensitivity. However, the use of ESI imposes limitations on the composition of the separation buffer that can be used in the CE separations. To reduce problems with ion suppression, background cluster ions and contamination of the MS ion optics, a volatile buffer is the choice. The performance of the CE separations will normally increase with higher ionic strength, while the high ionic strength is a disadvantage in ESI-MS; therefore, compatibility of the separation buffer with the electrospray process and the resulting mass spectrometric analysis must be considered. A relevant point is that the $\mathrm{CE}$ column exits at atmospheric pressure which preserves the pressure profile within the column and maintains the resolution.

When coupling CE/MS and immunoaffinity interactions, it is important to first optimize immunoextraction. As in SPE, Delanay-Bertoncini and Hennion ${ }^{50}$ divide the immunoextraction procedure in five different steps: (1) conditioning; (2) sample application; (3) washing, (4) elution of the target analyte; and (5) regeneration. The conditioning step removes the immunosorbent storage solution, and should be performed with an appropriate buffer solution that creates a favorable environment for specific interactions between the target analyte and the immunosorbent. During the second step, sample application, it is important to prevent any loss in recovery that can result from an overloading of the immunosorbent capacity and/or low affinity of antibodies toward s the 
compounds of interest. Washing, the third step, removes interferences without eluting the analyte. The purpose of the washing step is to minimize the interference of measurement. Strong washing solutions can effectively remove interfering components; however, they may elute the analytical components. The fourth step, elution of the target analyte, can be done by a number of different approaches: displacer agents, chaotropic reagents, $\mathrm{pH}$ variations, and water-organic modifier mixtures. Wieboldt et al., ${ }^{30}$ describes the use of a benzodiazepine-specific antibody for screening small-molecule libraries. In this work, the authors use centrifugal ultrafiltration to separate the non-bonded analytes from the Abdrug complex. The disruption of the affinity complex collected on the filter and the elution of the benzodiazepines was performed through the addition of $30 \mu \mathrm{L}$ of $1 \%$ trifluoroacetic acid in water to the filter. According to the authors, elution with $1 \%$ TFA was sufficient to completely desorb the most strongly bound compounds from the antibodies. They also noted that elution with a $20 \%$ acetic acid solution produced identical results. The fifth step, the regeneration step, is required for immunosorbent reusability; this step is not recommended when complex samples are analyzed. The goal of this portion of the project was to evaluate the binding capacity of the prepared immunosorbent by measuring the amount of benzodiazepine captured by the immunosorbent.

\section{Materials and methods}

\section{Reagents}

Flunitrazepam and diazepam standards were purchased at $1.0 \mathrm{mg} / \mathrm{ml}$ in methanol from Cerilliant (Round Rock, TX USA) 


\section{Instrumentation}

A capillary electrophoresis system (Agilent) connected to a time-of-flight (TOF) mass spectrometer (Agilent) equipped with an orthogonal electrospray interface, using the following operational parameters: Capillary Voltage, $3800 \mathrm{~V}$; Nebulizer pressure, 5 psi; Drying gas, $5 \mathrm{~L} / \mathrm{min}$; Gas temperature, $300^{\circ} \mathrm{C}$; Fragmentor voltage, $225 \mathrm{~V}$; Skimmer voltage, 60V; Octapole RF, 300V; Mass Range (m/z), 50-1000; Resolution, 9500 \pm 500 (922.0098); References masses, 121.0509 and 922.0098. The sheath fluid liquid was composed of methanol/water $(50 / 50 \mathrm{v} / \mathrm{v})$, containing formic acid $(0.1 \% \mathrm{v} / \mathrm{v})$. The flow rate was $0.5 \mathrm{ml} / \mathrm{min}$ with a $1 / 1000$ split ratio. ${ }^{51}$ Capillaries with a polyimide coating from Polymicro Technologies (Phoenix, AZ) had $50 \mu \mathrm{m}$ ID and were $80 \mathrm{~cm}$ long. New capillaries were conditioned at 10 bar with methanol for ten minutes, water for $0.5 \mathrm{~min}$, $0.1 \mathrm{~N} \mathrm{HCL}$ for ten minutes, water for 2 minutes, $1 \mathrm{~N} \mathrm{NaOH}$ for ten minutes, water for 10 minutes, and finally with running buffer (10 $\mathrm{mM}$ ammonium acetate) for 10 minutes. At the end of these steps the capillary was conditioned and filled with running buffer. Capillaries were coupled to the mass spectrometer via a sheath flow ESI interface (Agilent).

\section{Antibody Binding assay:}

In order to check the performance of the antibody a binding assay was performed based on the work done by Wieboldt ${ }^{30}$. This assay consisted of an incubation of $100 \mu 1$ of a $50 \mu \mathrm{g} / \mathrm{ml}$ of flunitrazepam (or diazepam) in $10 \mathrm{mM}$ ammonium acetate $\mathrm{pH} 6.5$ or $0.1 \mathrm{M}$ phosphate buffer $\mathrm{pH} 7.2$ with different stoichiometric amounts of antibody. After $1 \mathrm{~h}$ incubation the solution was diafiltered, and washed two times with ammonium acetate buffer $\mathrm{pH} 6.5$ or $0.1 \mathrm{M}$ phosphate buffer $\mathrm{pH}$ 7.2. Then, $30 \mu \mathrm{l}$ of a $20 \%$ acetic acid or 70:30 
methanol: water solution was added, incubated for 30 minutes and the solution separated by ultrafiltration. The recovered liquid was dried at vacuum and reconstituted in $30 \mu \mathrm{l}$ of ammonium acetate pH6.5 buffer. The reconstituted liquid was analyzed by CE-MS using $10 \mathrm{mM}$ ammonium acetate pH6.5 buffer as the CE buffer. Sample was applied by hydrodynamic injection at the capillary inlet at 10.0 mbar for $5 \mathrm{~s}$. Separation was performed under a positive voltage of $30.0 \mathrm{kV}$. The temperature of the capillary cartridge was set at $25^{\circ} \mathrm{C}$. The TOF-MS analysis was performed in positive ion mode. References masses (Purine at $121.0509 \mathrm{~m} / \mathrm{z}$ and HP0921 at $922.0098 \mathrm{~m} / \mathrm{z}$, resolution of $9500 \pm 500$ ) were added to the sheath fluid liquid and continuously monitored to maintain the instrument's calibration. ${ }^{51}$ Data analysis was performed using Applied Biosystems/MDSSciex Analyst QS software (Frankfurt, Germany)

\section{Immunosorbent binding assay:}

The immunosorbent $(10 \mathrm{mg}$ ) was combined with $200 \mu \mathrm{lof} 50 \mu \mathrm{g} / \mathrm{ml}$ flunitrazepam or

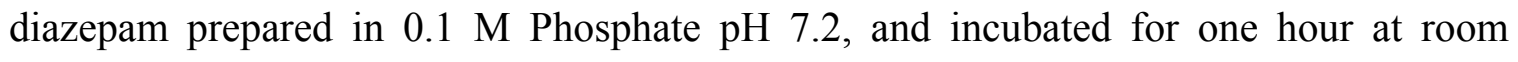
temperature. The solution was transferred to a $2 \mu \mathrm{m}$ filter and centrifuged at $1000 \mathrm{~g}$ for five minutes. The immunosorbent was washed three times with $100 \mu 1$ of $0.1 \mathrm{M}$ phosphate buffer $\mathrm{pH} 7.2$, three times with $100 \mu 1$ of $10 \mathrm{mM}$ ammonium acetate $\mathrm{pH} 6.5$ and incubated for 30 min with $75 \mu \mathrm{l}$ of $20 \%$ acetic acid or $70: 30$ methanol: water solution. One again the solution was transferred to a $2 \mu \mathrm{m}$ filter and centrifuged at $1000 \mathrm{~g}$ for five minutes. The immunosorbent was saved for additional testing and the solution was vacuum dried and reconstituted with $30 \mu 1$ of $10 \mathrm{mM}$ ammonium acetate $\mathrm{pH} 6.5$ and analyzed by CEMS using $10 \mathrm{mM}$ ammonium acetate $\mathrm{pH} 6.5$ as the $\mathrm{CE}$ buffer. 


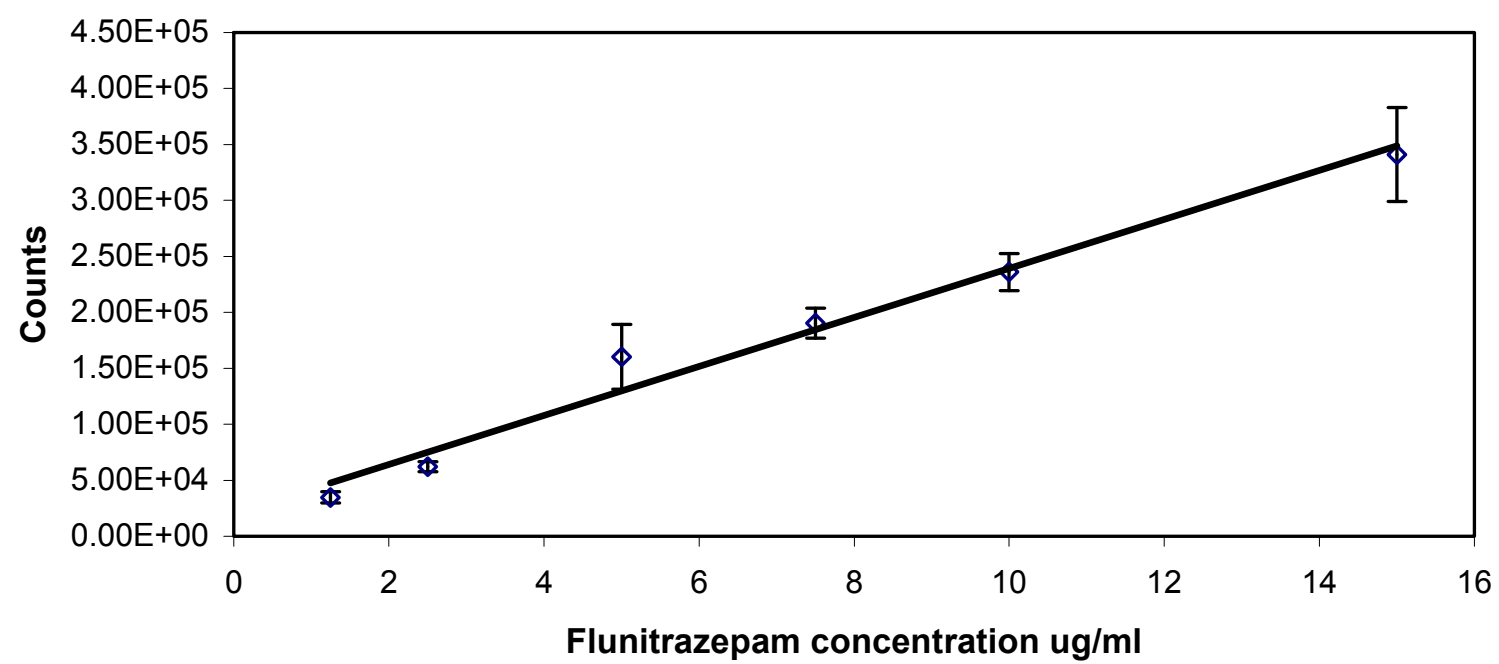

Fig 10 Calibration curve for flunitrazepam in the range from 1.25 to $15 \mu \mathrm{g} / \mathrm{ml}$. Standards were prepared in $10 \mathrm{mM}$ ammonium acetate $\mathrm{pH} 6.5$ from $1 \mathrm{mg} / \mathrm{ml}$ solution of flunitrazepam in methanol. They were analyzed by CE-MS using $10 \mathrm{mM}$ ammonium acetate pH6.5 as the CE buffer and applied by hydrodynamic injection at the capillary inlet at 10.0 mbar for $5 \mathrm{~s}$. Separation was performed under a positive voltage of $30.0 \mathrm{kV}$. The temperature of the capillary cartridge was set at $25^{\circ} \mathrm{C}$. The TOF-MS analysis was performed in positive ion mode. References masses (Purine at $121.0509 \mathrm{~m} / \mathrm{z}$ and HP0921 at $922.0098 \mathrm{~m} / \mathrm{z}$, resolution of $9500 \pm 500$ ) were added to the sheath fluid liquid and continuously monitored to maintain the instrument's calibration. ${ }^{51}$ Data analysis was performed using Applied Biosystems/MDS-Sciex Analyst QS software (Frankfurt, Germany). The corresponding equation and coefficient of correlation are: $\mathrm{y}=2.01 \mathrm{E} 4+$ $2.19 \mathrm{E} 4 \mathrm{x}, \mathrm{r}^{2}=0.9893$. The error bars represents a range of \pm 1 standard deviation. 


\section{Elution testing for the immunosorbent:}

In order to improve the extraction (maximize the extracted drug) and to preserve the immunosorbent performance, a test was developed to select the best solution for extracting the binding drug. The test utilized was the same as the one used in the immunosorbent binding assay procedure, but with some modifications: First different solutions were used for drug elution; The tested solutions were methanol: water at concentrations of 10:90, 30:70, 50:50, and 70:30. Second elutions were assayed consecutively: i.e. there was no additional drug-immunosorbent incubation, and third, the solution injected into the capillary was the one used for extraction without any vacuum concentration.

\section{Results and discussion:}

The preliminary binding trials were performed on crude antibody using $10 \mathrm{mM}$ ammonium acetate buffer as the binding medium and a $100 \mu 1$ of a $50 \mu \mathrm{g} / \mathrm{ml}$ of flunitrazepam solution, unfortunately the binding of drug to the antibody was negligible. This solution was chosen because it was the running buffer in the CE separation and so fewer washing steps were needed. Better results were obtained using $0.1 \mathrm{M}$ phosphate buffer pH 7.2 as the binding medium. Subsequent experiments were performed using 100 $\mu \mathrm{l}$ of $0.1 \mathrm{M}$ phosphate buffer $\mathrm{pH} 7.2$ with some additional washes steps. The purpose of the first washing step (0.1 M Phosphate buffer $\mathrm{pH}$ 7.2) was to eliminate non-specific binding, which could cause false positive results. Prior to elution, a second washing step was used involving $100 \mu \mathrm{l}$ of $10 \mathrm{mM}$ ammonium acetate $\mathrm{pH}$ 6.5. The purpose of this step was to remove residual phosphate in the sample which might contaminate the ion detector in the MS system. 
The binding assay was performed on the sample as received, with no purification. The obtained value was $0.3 \mathrm{mg}$ of flunitrazepam/gram of antibody.

Because this result was very low when compared with reports from other authors, the possibility of an unpurified antibody was considered, and a scheme for purification was developed as was described in the chapter II (Immunosorbent Preparation). Once a pure antibody was available the binding test was performed again, but because only a small amount of antibody was available, the binding assay was not performed on the antibody but on the immunosorbent which was prepared as previously described. The drug bound on $11.5 \mathrm{mg}$ of immunosorbent was $0.45 \pm 0.12 \mu \mathrm{g}$ of flunitrazepam. If the amount of antibody attached to the activated silica was $17 \mathrm{mg}$ of antibody $/ \mathrm{g}$ of silica, a binding value of $2.3 \pm 0.6 \mathrm{mg}$ of flunitrazepam/ $\mathrm{g}$ of antibody or $39 \pm 10 \mu \mathrm{g}$ of flunitrazepam/ $\mathrm{g}$ of immunosorbent was determined. This value is $62 \%$ of the theoretical value $(4.17 \mathrm{mg}$ of flunitrazepam/ $\mathrm{g}$ of antibody) and is very close to that reported by DelaunayBertoncini ${ }^{13}$ which was $38 \mu \mathrm{g}$ of isoproturon/g of bonded silica. As can be seen from the results, a dramatic improvement ( 0.3 vs. $2.6 \mathrm{mg}$ drug/g antibody) was reached using a purified antibody. This can be explained by the fact that more binding sites were now available on the support.

When performing the elution of Flunitrazepam from the prepared immunosorbent using $20 \%$ acetic acid a change in color was observed in the immunosorbent. This may be because at lower pHs silica suffers degradation with the result that the antibody can be released from the silica substrate. Alternatively the low $\mathrm{pH}$ value may produce a permanent denaturation of the antibody, causing a dramatic loss in its binding properties. In order to minimize denaturation, an elution solution must be selected which does not 
damage the immunosorbent and at the same time is enough strong to completely disrupt the antibody-drug interaction to give high recovery of the drug. Another requirement of the elution solution is that it must work when used in small amounts, in order to yield narrow peaks for efficient separations.

In order to look for the best elution solution a test similar to the binding assay was performed by washing the immunosorbent with different solutions. According to Delaunay-Bertoncini et al, ${ }^{52}$ elution conditions using water-organic modifier mixtures are commonly required to elute small molecules but, because these conditions can irreversibly denature antibodies, small volumes and short contact times should be used. These two conditions are highly favorable for use with on-line solid phase extraction because with small volumes, as mentioned earlier, narrow peaks can be obtained and, with short contact time a fast analysis time can be realized. Experiments were therefore performed by examining an elution solution containing a low content of methanol (methanol:water 10:90) while monitoring recovered value of target compound, then the concentration of methanol was gradually increased from $30 \%$ to $70 \%$ determining its effect on recovery. This test was performed on the previously characterized immunosorbent, by consecutive extractions, and with no preconcentration step i.e. drug was extracted with methanol: water and injected directly into the MS instrument. As can be seen on table 1 , concentrations lower than $70 \%$ in methanol were not strong enough to elute the total binding drug, which can be eluted using $70 \%$ methanol: water. This can be confirmed by the fact that an additional extraction with $20 \%$ acetic acid did not release additional drug. Also, on table 1 it can be seen that at a ratio of $70 \%$ methanol: water a new peak at m/e 346 appeared (Fig. 12) in addition to the normal peak at m/e 314 which 
was the protonated flunitrazepam. This peak can be assigned as $\left[\mathrm{M}+\mathrm{CH}_{3} \mathrm{OH}_{2}\right]^{+}$an ion adduct, with a molecular weight of 346. Unfortunately this adduct did not appear when the standards were prepared in methanol: water $70: 30$, possibly because the adduct formation is favored by the silica- drug-methanol interaction. Because this peak could not be reproduced its quantitation was not possible

A second immunosorbent was prepared following the same preparation procedure, but elution was performed using $70 \%$ methanol: water. This immunosorbent gave a value of $34 \pm 7 \mu \mathrm{g}$ of flunitrazepam/ $\mathrm{g}$ of immunosorbent $(2.1 \pm 0.4 \mathrm{mg}$ flunitrazepam / $\mathrm{g}$ of antibody, $50 \%$ of the theoretical value). The similarity between the binding values obtained with these two different immunosorbents demonstrates the reproducibility of the preparation procedure, and prove that a concentration of $70 \%$ methanol: water works similarly to as $20 \%$ acetic acid.

In order to determine the quantity of $70 \%$ methanol: water necessary to completely elute the bound flunitrazepam, a test was performed by doing consecutive extractions with 75 $\mu \mathrm{L}$ of $70 \%$ methanol: water. The extracted drug was $0.14 \mu \mathrm{g}$ in the first extraction, and no drug was detected on the second and third extractions. From this result it can be postulated that $75 \mu \mathrm{L}$ of $70 \%$ methanol: water is enough to disrupt the antibody-drug complex. The absorbent's capacity from this trial was $14 \mu \mathrm{g}$ flunitrazepam/ $\mathrm{g}$ immunosorbent. It can be seen that the immunosorbent lost about $59 \%$ of its initial retention capacity ( $34 \pm 7 \mu \mathrm{g}$ of flunitrazepam/g of immunosorbent).

Overall, the retention capacity for the immunosorbent prepared as previously described (chapter two) was $39 \pm 10 \mu \mathrm{g}$ of flunitrazepam/g immunosorbent. The fact that another immunosorbent prepared with the same technique gave a similar retention capacity $(34 \pm$ 
$7 \mu \mathrm{g}$ of flunitrazepam/ $\mathrm{g}$ of immunosorbent) demonstrates the reproducibility and efficacy of the preparation method.

$70 \%$ methanol: water was shown to be the best solution to completely elute the bound drug from the immunosorbent, and $70 \mu \mathrm{L}$ of this mixture was sufficient to completely elute the drug contained in the quantity of immunosorbent tested.

The observed change in appearance, and the decrease in retention capacity of the immunosorbent, indicated the possibility that the immunosorbent suffers some sort of degradation during the elution process. Some authors have suggested that silica at $\mathrm{pH}$ greater than five (especially at neutral $\mathrm{pH}$ ) can suffer loss of aminopropyl groups as a result of the autocatalytic effect of the amino group. ${ }^{56,57}$ 


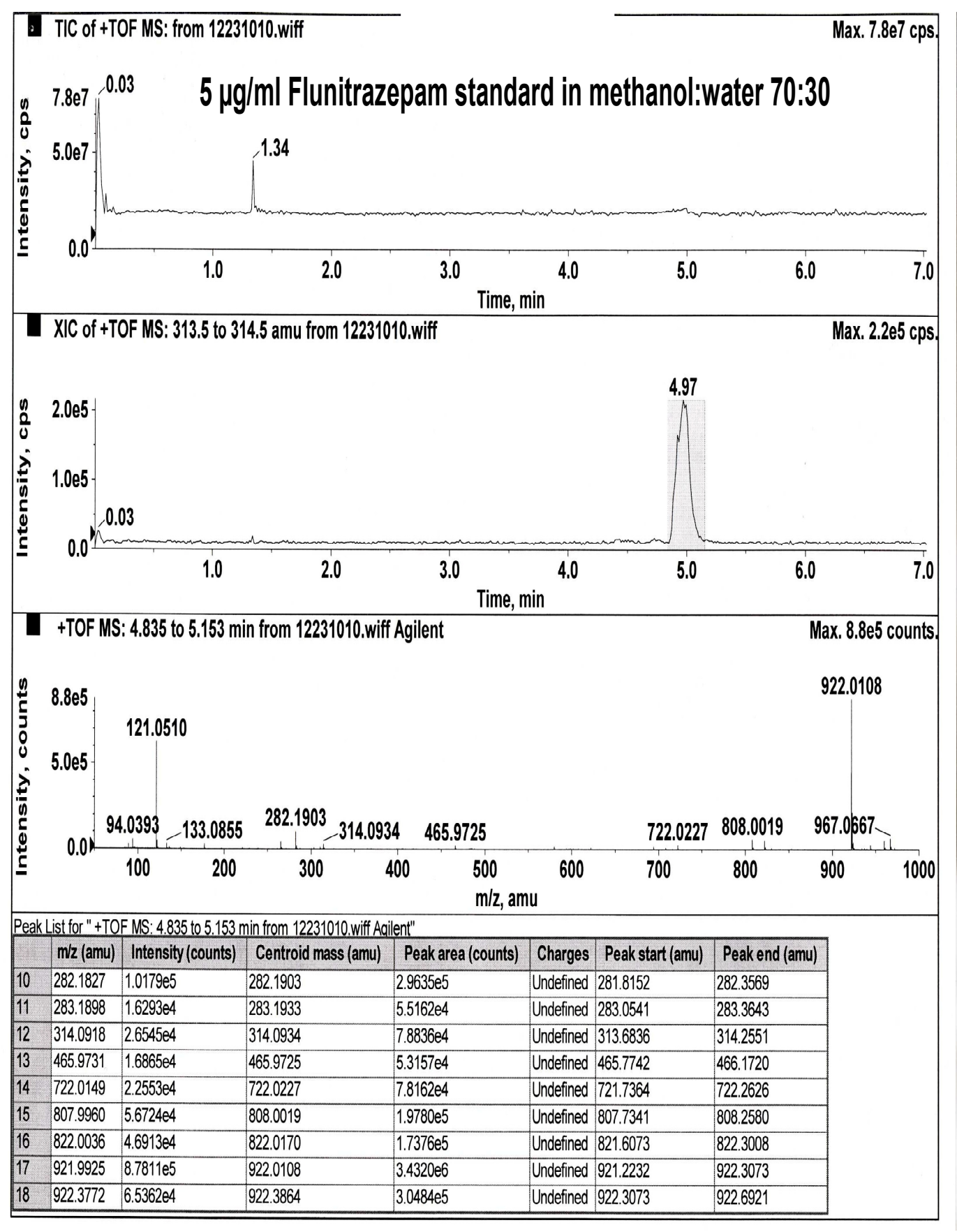

Figure 11. Ion electrochromatogram of $5 \mu \mathrm{g} / \mathrm{ml}$ flunitrazepam standard. Analysis was performed by using $10 \mathrm{mM}$ ammonium acetate $\mathrm{pH} 6.5$ as the CE buffer and applied by hydrodynamic injection at the capillary inlet at 10.0 mbar for $5 \mathrm{~s}$. Separation was performed under a positive voltage of $30.0 \mathrm{kV}$. The temperature of the capillary cartridge was set at $25^{\circ} \mathrm{C}$. The TOF-MS analysis was performed in positive ion mode. References masses (Purine at $121.0509 \mathrm{~m} / \mathrm{z}$ and HP0921 at $922.0098 \mathrm{~m} / \mathrm{z}$, resolution of $9500 \pm 500$ ) were added to the sheath fluid liquid and continuously monitored to maintain the instrument's calibration. ${ }^{51}$ 


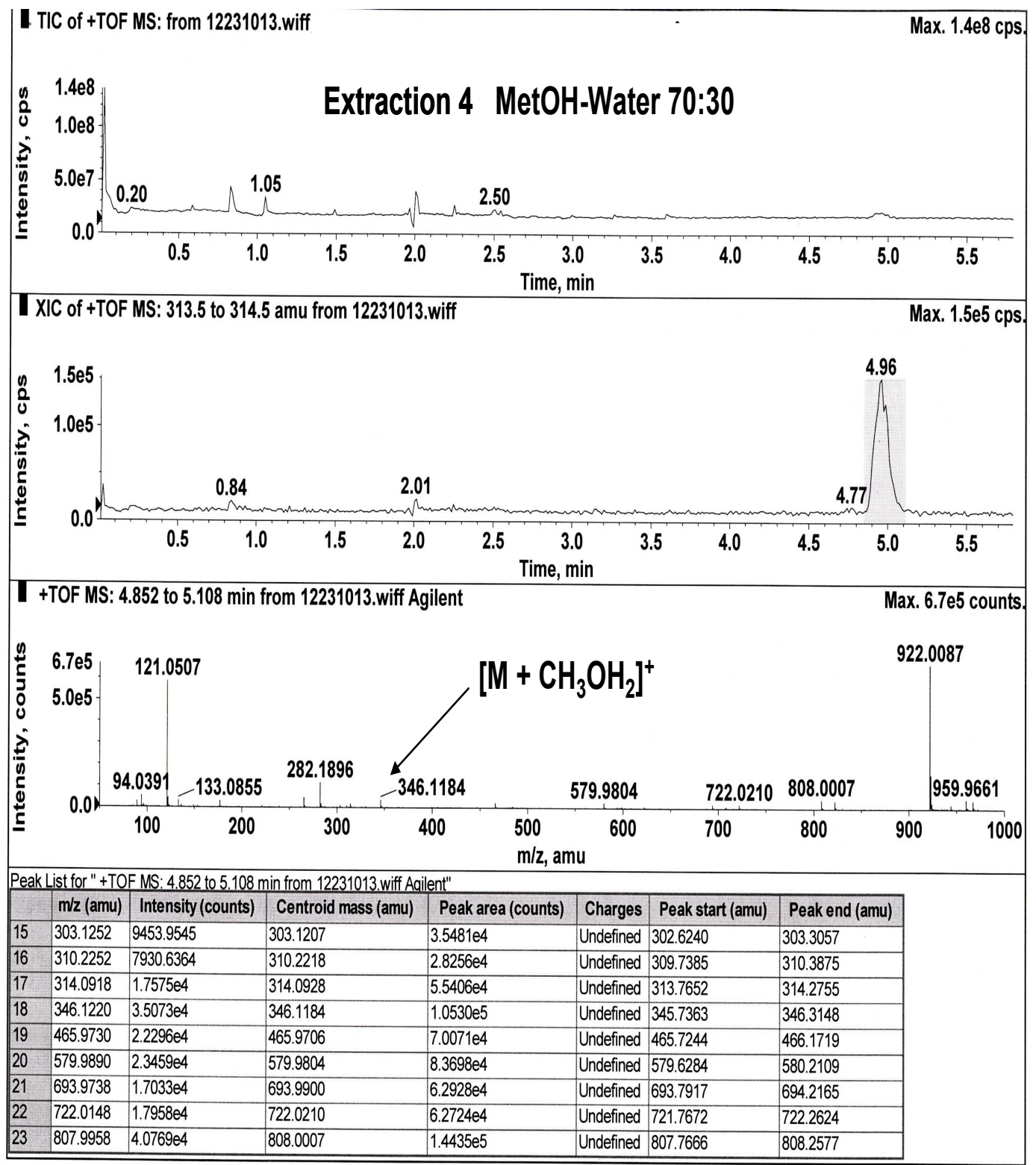

Figure 12 Ion electrochromatogram of extracted flunitrazepam. The presence of a new peak at $\mathrm{m} / \mathrm{z}=346$ can be seen, this peak can be due to the adduct formation of $\left[\mathrm{M}+\mathrm{CH}_{3} \mathrm{OH}_{2}\right]^{+}$. See fig 10 and text for conditions. 


\begin{tabular}{|c|c|c|c|}
\hline Extraction & $\begin{array}{c}\text { Elution Solution } \\
\text { Ratio methanol:water }\end{array}$ & $\begin{array}{c}\text { Recovered Flunitrazepam } \\
\mu \mathrm{g}\end{array}$ & $\begin{array}{c}\text { Peak area at m/z=346 } \\
\text { (Counts) }\end{array}$ \\
\hline 1 & $10: 90$ & 0.02 & - \\
\hline 2 & $30: 70$ & 0.03 & $3.3407 \mathrm{E} 4$ \\
\hline 3 & $50: 50$ & 0.02 & $1.0530 \mathrm{E} 5$ \\
\hline 4 & $70: 30$ & 0.01 & - \\
\hline 5 & $20 \%$ Acetic acid & ND & \\
\hline
\end{tabular}

Table 1. Effect of increasing percentage of methanol on extraction of binding drug. Experiments were performed by examining an elution solution containing a low content of methanol (methanol:water 10:90) while monitoring recovered value of target compound, then the concentration of methanol was gradually increased from $30 \%$ to $70 \%$ determining its effect on recovery. This test was performed by consecutive extractions, and with no preconcentration step i.e. drug was extracted with methanol:water and injected directly into the MS instrument. 


\section{Chapter IV: Stability Improvement:}

\section{Introduction:}

There are two cases of ligand leakage in immunosorbents: leakage into simple aqueous solution systems during the storage of immunosorbent, and leakage during inmunoadsorption treatment, where unknown enzymes and other substances may play a role in releasing the ligand. ${ }^{53}$ Immunosorbent stability depends on the concentration and conformation of the bonded antibodies, and the chemical stability of the support. Furthermore, deterioration can occur under external pressure, or as a result of swelling caused by the different solvents. Dissociation of the antibody-analyte complex is the step that can produce the most damage to the immunosorbent. The use of a very low $\mathrm{pH}$ for desorption improved the elution, but induced a more rapid loss of antibody activity.

The chemical stability of the support is a critical issue when performing immunoextraction. The stability of silica in aqueous medium depends on $\mathrm{pH}$ and decreases drastically in alkaline medium. When a silica surface is functionalized with amino groups it is expected that the basic character of this function may affect the overall chemical stability ( and reactivity) of the resulting functionalized silica. Etienne and Walcarius ${ }^{54}$ have studied the chemical reactivity and stability of aminopropylfunctionalized silica (APS). They studied the influence of $\mathrm{pH}$ on the dissolution of APS materials in aqueous medium by monitoring the total soluble silicon-containing species that have leached in solution as a function of time and found that the initial $\mathrm{pH}$ of the suspension has a dramatic effect on the quantity of silicon species liberated in solution, even during the first few minutes. The extent of solubilization is very low at $\mathrm{pH}=1$, much higher at $\mathrm{pH}=5.7$, and maximal when the solution $\mathrm{pH}$ is not controlled, enabling the 
material to express its total basicity. In a second experiment they compared the behavior of silica based materials in the presence and absence of amino groups that were either dispersed in solution or immobilized at the silica surface. By comparing these two treatments, it appears that APS dissolution in aqueous medium is mainly due to the presence of amino groups. By these experiments, and several others realized by the authors, they concluded that amino groups grafted on the surface of silica gel exist under two different forms "free" unprotonated amine $\left(\equiv \mathrm{SiO}-\mathrm{C}_{3} \mathrm{H}_{6}-\mathrm{NH}_{2}\right)$ and zwitterion-like species $\left(\equiv \mathrm{SiO}^{-},+\mathrm{H}_{3} \mathrm{NC}_{3} \mathrm{H}_{6}-\mathrm{Si} \equiv\right)$. These latter forms are much more stable in aqueous solution (several hours) while the first ones contribute to a fast hydrolysis reaction of $\mathrm{Si}-\mathrm{O}-\mathrm{Si}$ bonds, leading to the leaching of aminopropylsilane.

Smith and Chen ${ }^{55}$ found that all surfaces prepared from 3-aminopropyl silanes under all conditions studied exhibit hydrolysis, suggesting that the $\gamma$-aminopropylsiloxane structure is inherently more reactive than other aminoalkylsiloxanes due to their ability to form stable cyclic intermediates. They suggest that aminosilanes with shorter or longer alkyl linkers than propyl may be good candidates for aqueous applications.

It can be postulated that the immunosorbent instability was the result of two issues. First, the antibody suffers denaturation at low $\mathrm{pH}$. This problem can be avoided by the use of $70 \%$ methanol: water as elution solution, and secondly, the remaining amino groups (amino groups that do not react with SMCC) caused an autocatalytic reaction which breaks the bonding between the silica support and the functionalized amino groups, releasing the attached antibody, and as a result a decreasing binding capacity. The next step was to improve the immunosorbent stability by capping the remaining amino groups 
through reaction with acetic anhydride. It was postulated that with the absence of free amino groups a more stable immunosorbent might be obtained.

\section{Materials and Methods:}

Chemicals and instrumentation described in chapter II and III were also used in this chapter. Diazepam was purchased from Cerilliant (Round Rock, TX, USA) as a $1 \mathrm{mg} / \mathrm{ml}$ in methanol.

\section{Silica Preparation:}

In order to prepare a more stable immunosorbent, a new preparation process was examined in order to cap the remaining amino groups on the silica support: ${ }^{24}$ The preparation process was similar to the one previously developed with one difference: the amino groups remaining on the SMCC activated silica were capped using acetic anhydride. To prepare the immunosorbent, $17 \mathrm{mg}$ of amino silica was reacted for $21 \mathrm{~h}$ at room temperature with $400 \mu 1$ of dimethyl formamide (DMF) which contained $13 \mu \mathrm{M}$ of succinimidyl 4-(N-maleidomethyl)-cyclohexane -1-carboxilate (SMCC) and $4 \mu \mathrm{M}$ of 4dimethyl-aminopyridine (DMAP). Then the silica was transferred to a $2 \mu \mathrm{m}$ filter and centrifuged at $1000 \mathrm{~g}$ until the activated silica appeared dry. Capping was performed by taking the activated silica and adding it to $80 \mu \mathrm{L}$ of a 1:1 mixture of acetic anhydride and pyridine containing $2 \mathrm{mg}$ of DMAP. The mixture was stirred in the dark for 24 hours. The capped silica was washed three times with acetonitrile, three times with diethyl ether, and dried under vacuum. Prior to immobilization the capped silica was washed three times with $0.1 \mathrm{M}$ phosphate buffer $\mathrm{pH}$ 7.2. The antibody immobilization was done as previously reported with no modification. 


\section{Immunosorbent stability:}

The immunosorbent stability was tested by performing a binding assay at a series of time intervals on the newly prepared immunosorbent, using diazepam as the binding drug. Figure 13 shows the calibration curve for diazepam and table 2 shows the results obtained. As can be seen the immunosorbent performance reached a peak at time zero i.e. just after preparation and, showed a decrease in performance of about $11 \%$ when it was tested on the same day for a second binding assay. From the graph it can be seen that the immunosorbent performance remains almost stable after three weeks of storage and, shows a decrease in performance of about $63 \%$ after four weeks of preparation.

Based on these results a new immunosorbent was prepared and its retention capacity was tested. One week after preparation was chosen as the time for initiating the stability test to determine the number of times the immunosorbent could be used without its performance being affected. 


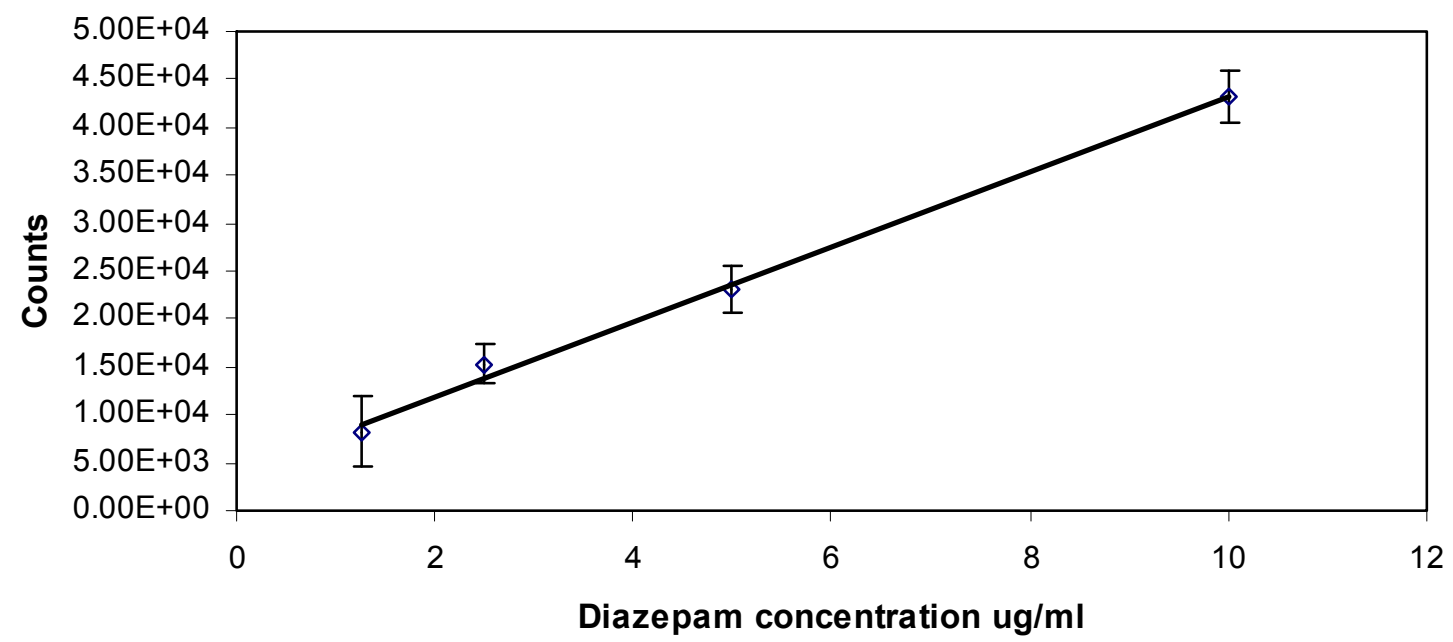

Figure 13. Calibration curve for diazepam in the range from 1.25 to $10 \mu \mathrm{g} / \mathrm{ml}$. Standards were prepared in $10 \mathrm{mM}$ ammonium acetate $\mathrm{pH} 6.5$ from $1 \mathrm{mg} / \mathrm{ml}$ solution of diazepam in methanol. They were analyzed by CE-MS using $10 \mathrm{mM}$ ammonium acetate pH6.5 as the CE buffer and applied by hydrodynamic injection at the capillary inlet at 10.0 mbar for $5 \mathrm{~s}$. Separation was performed under a positive voltage of $30.0 \mathrm{kV}$. The temperature of the capillary cartridge was set at $25^{\circ} \mathrm{C}$. The TOF-MS analysis was performed in positive ion mode. References masses (Purine at $121.0509 \mathrm{~m} / \mathrm{z}$ and HP0921 at 922.0098 $\mathrm{m} / \mathrm{z}$, resolution of $9500 \pm 500$ ) were added to the sheath fluid liquid and continuously monitored to maintain the instrument's calibration. ${ }^{51}$ Data analysis was performed using Applied Biosystems/MDS-Sciex Analyst QS software (Frankfurt, Germany). The corresponding equation and coefficient of correlation are: $\mathrm{y}=4.31 \mathrm{E} 3+3.85 \mathrm{E} 3 \mathrm{x}$, $\mathrm{r}^{2}=0.9868$. The error bars represents a range of \pm 1 standard deviation. 


\begin{tabular}{|c|c|c|c|c|}
\hline Week & Binding test 1 & Binding test 2 & Binding test 3 & Binding test 4 \\
& $\mu \mathrm{g}$ diazepam/g IS & $\mu \mathrm{g}$ diazepam/g IS & $\mu \mathrm{g}$ diazepam/g IS & $\mu \mathrm{g}$ diazepam/g IS \\
\hline 0 & 27 & 18 & - & - \\
\hline 3 & 16 & 18 & - & 6 \\
\hline 4 & 8 & 10 & 6 & \\
\hline
\end{tabular}

Table 2. Stability of the immunosorbent. The values represents the amount of drug extracted with a solution methanol:water 70:30 in $\mu \mathrm{g}$ of diazepam/gram of immunosorbent. The test was designed to test how the capping step, improved the performance of the immunosorbent. To perform this test the immunosorbent $(10 \mathrm{mg})$ was combined with $200 \mu \mathrm{l}$ of $50 \mu \mathrm{g} / \mathrm{ml}$ diazepam prepared in $0.1 \mathrm{M}$ Phosphate $\mathrm{pH} 7.2$, and incubated for one hour at room temperature. The solute on was transferred to a $2 \mu \mathrm{m}$ filter and centrifuged at $1000 \mathrm{~g}$ for five minutes. The immunosorbent was washed three times with $0.1 \mathrm{M}$ phosphate buffer $\mathrm{pH} 7.2$, three times with $10 \mathrm{mM}$ ammonium acetate $\mathrm{pH} 6.5$ and incubated for $30 \mathrm{~min}$ 70:30 methanol: water solution. One again the solution was transferred to a $2 \mu \mathrm{m}$ filter and centrifuged at $1000 \mathrm{~g}$ for five minutes. The immunosorbent was saved for additional testing and the solution was vacuum dried and reconstituted with $30 \mu \mathrm{l}$ of $10 \mathrm{mM}$ ammonium acetate and analyzed by CE-MS using $10 \mathrm{mM}$ ammonium acetate $\mathrm{pH} 6.5$ as the CE buffer. 


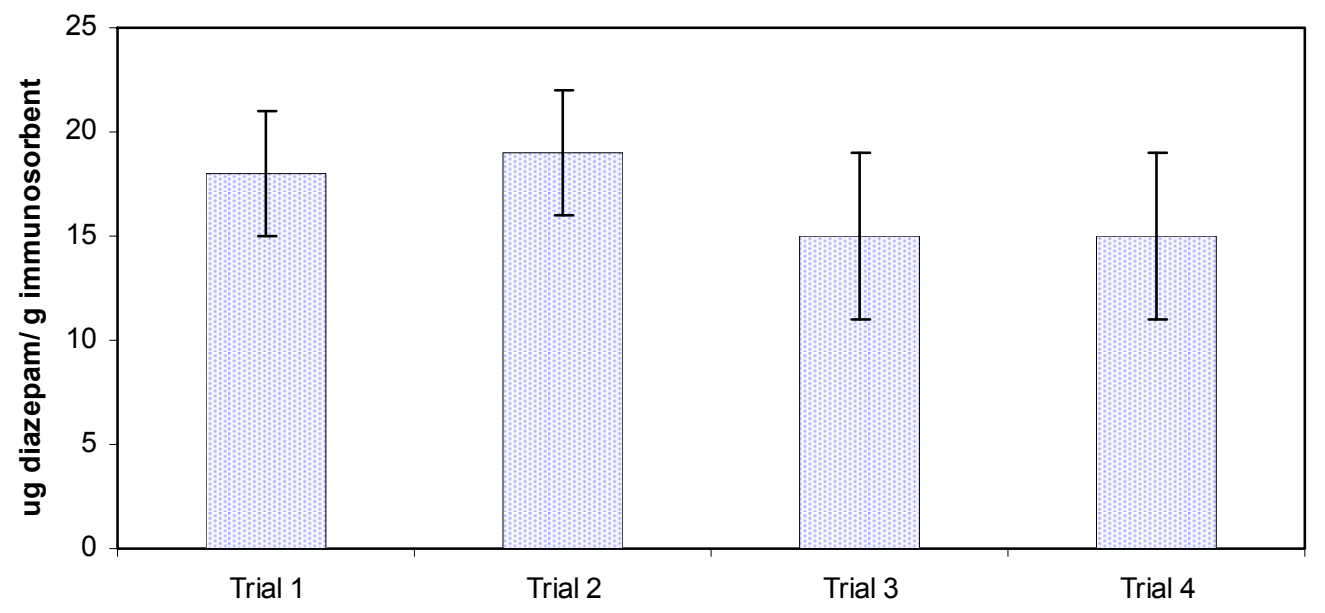

Figure 14 Reproducibility testing for the capped diazepam immunosorbent. The values represents the amount of drug extracted with a solution methanol:water 70:30 in $\mu \mathrm{g}$ of diazepam/gram of immunosorbent. The test was designed based on the results obtained from the previous experiment, and one week was chosen to perform the test, four test were performed to evaluate the performance of the immunosorbent after consecutive use. The binding assay was performed as described previously. 


\section{Results and discussion:}

After two tests of the immunosorbent its binding capacity was found to decrease to the point that it was no longer detected. Some authors have reported that aminosilica can suffer auto degradation, due to the high basicity of the amino groups. ${ }^{54,55}$ This degradation is more prevalent at $\mathrm{pH}$ greater than five. It is possible that this degradation can be minimized by capping these amino groups; this capping reaction can be performed by reacting the free amino groups with acetic anhydride.

Tests for stability improvement using the new procedure were performed using a different antibody than the one used in the preliminary studies. For these studies, a diazepam specific antibody was used. This antibody was chosen because it was prepurified which saved preparation time. In order to evaluate the antibody a binding capacity test was performed using the procedure mentioned earlier. Because the goal of the study was to analyze flunitrazepam, this binding assay was performed using flunitrazepam as the analyte. The result obtained for this binding test was $0.4 \mu \mathrm{g}$ flunitrazepam/ mg antibody. Because this level was relatively low, a new test was performed, however in this case diazepam was chosen as the binding drug. The binding capacity for the new test was $1.7 \pm 0.5 \mu \mathrm{g}$ of diazepam $/ \mathrm{mg}$ of antibody, four times larger than the value obtained using flunitrazepam as the binding drug. This higher value was consistent with the fact that the antibody was raised against diazepam, so it is more retentive towards diazepam than flunitrazepam.

Once the antibody was evaluated, a new immunosorbent was prepared but in this case an additional step was included. The remaining amino groups that did no react with the SMCC were treated with acetic anhydride in the presence of dimethyl amino pyridine as 
alkylation catalysts. After a twenty four-hour reaction the capped silica was washed several times and antibody was binding as previously described. As was mentioned, this additional step was performed to eliminate the remaining amino groups which presumably are responsible for the silica degradation and low binding capacity obtained following use. Note no additional characterization of the immunosorbent was performed at this point.

To evaluate the immunosorbent stability a series of binding test were scheduled for the same day of preparation and several weeks later, following storage of the immunosorbent in phosphate buffer $\mathrm{pH} 7.2$ at $4^{\circ} \mathrm{C}$. Two binding tests were performed immediately after immunosorbent preparation and subsequently two binding tests at week three and four binding test at week four. The results can be seen on table 2. It can be observed that around $33 \%$ of the immunosorbent performance has been lost when the immunosorbents has been tested the same day of preparation, and the immunosorbent retains its binding its binding capacity after three weeks of storage ( $11 \%$ loss based on the second binding test). A $70 \%$ loss of binding capacity can be seen after four weeks of preparations, and this value remains almost constant for the remaining trials that were performed the same day. The fact that the immunosorbent's binding capacity was retained after its second use was significant, since when the immunosorbent was prepared with no capping of the remaining amino groups, its binding capacity was completely lost once it has been used for the second time.

The dramatic lost of performance observed after the first use can be due to remaining uncapped amino groups which cause a fast initial degradation of silica as suggested by Etienne and Walcarius ${ }^{54}$, and worsened by the use of phosphate buffer which cause a 
more deleterious effect on silica than organic-based buffers ${ }^{56,57}$. Also, it has been reported by Mahon ${ }^{58}$ that silica dissolution is highly accelerated under biological ionic strength as oppose to pure water at room temperature. With these findings in mind it can be said that the loss in performance could also be due to the use of phosphate buffer as the washing and storage solution. Another cause of immunosorbent lost of performance could be the breaking of the bond between the SMCC and the amino group. This kind of leaching has been reported by Gomez de la Torre et al ${ }^{59}$ in their work where they conjugate oligonucleotides to magnetic nanobeads.

As can be seen on table 2 a very dramatic lost in performance occur at week four, where almost a $55 \%$ of binding capacity was lost (based on the binding test performed on week three). It can be speculated that degradation of silica caused by amino groups could be the result of hydrolysis of the acetamido bonds resulting in the presence of amino groups on the support surface, as reported by Björklund and Hearn ${ }^{60}$.

The fact that the immunosorbent retains its binding capacity after its first use at weeks three and four discards the possibility that the lost of performance was due to antibody denaturation caused by $70 \%$ methanol elution. These results also indicate that phosphate buffer at $\mathrm{pH} 7.2$ is an appropriate storage solution. Based on these results a new immunosorbent was prepared and its retention capacity was tested. One week after preparation was chosen as the time for testing the IS for the number of times the IS could be used without its performance being affected. From figure 14 it can be seen that the IS can be used for at least four times after one week of preparation, over which time a decrease in performance of about $20 \%$ occurs. 
Overall, from the data provided it can be conclude that the immunosorbent stability can be improved by the capping of the unreacted amino groups. There are some other variables which decrease the binding ability of the immunosorbent like the breaking of the bonds between the amino group and the SMCC molecule, the influence of ionic strength and the chemical composition of the buffer, which should be considered when developing a robust immunosorbent system. Although, the long term immunosorbent stability is not the best it can be said that the prepared immunosorbent shows a good performance when it is used as close as possible to the time of preparation. 


\section{Chapter V: Conclusions and Future Directions}

\section{Conclusions}

A solid phase immunosorbent was prepared from the reaction between amino silica and antibodies raised against flunitrazepam. The immunosorbent specific for flunitrazepam gave a binding value of $39 \pm 10 \mu \mathrm{g}$ of flunitrazepam/ $\mathrm{g}$ of immunosorbent. The preparation of the immunosorbent proved to be reproducible and reliable by the fact that a second immunosorbent was prepared following the same procedure and its binding value was very similar.

A purification scheme was developed for the purification of IgG antibody, which proved to be very efficient by the fact the no contaminants were present after purification.

The quantification of the amino groups on silica and on the antibody demonstrated very good agreement to the values reported for some authors.

The prepared immunosorbent has been tested as a solid phase extraction media for the analysis of flunitrazepam; its performance has been satisfactory from the point of view of retention and functionality.

The binding capacity was tested for an antibody specific for diazepam. Its value was 1.7 $\pm 0.5 \mu \mathrm{g}$ of diazepam/ mg of antibody.

The capping of the remaining amino groups on the support improved the stability of the immunosorbent. The capped immunosorbent retained its activity after several uses, whereas the immunosorbent with no capping that lost its activity just after the first use.

\section{Future Directions:}

The next step in performing analysis of benzodiazepines using antibodies immobilized on silica support is to test the immunosorbent using an in-line procedure. To do this the 
capillary column must be packed with the immunosorbent. The analysis could be done using UV-VIS detection which reduces the need for additional washing steps, thereby improving the immunosorbent performance and reducing the analysis time.

Additional drug classes could be analyzed by immobilization of different selective antibodies using the same preparation route and/or different supports like the mesoporous silica obtained by the sol-gel process. Using this type of process the packing procedure could be avoided because the sol-gel reaction can be performed inside the capillary. Additionally, by the proper choice of different precursors, a great variety of ligands may be utilized, given the opportunity to test different immobilization techniques.

The use of aptamers has been gained popularity by the fact that they are more resistant to harassing conditions like $\mathrm{pH}$, temperature and solvents than antibodies. Aptamers are single-stranded DNA or RNA ligands that can be selected for different targets starting from a huge library of molecules containing randomly created sequences. To develop an aptamer specific for benzodiazepines, its immobilization and testing in the determination of benzodiazepines and their metabolites in different matrices will be a way of continuing the study of binding of molecular recognition ligands.

It may be useful to study the influence of the phosphate buffer as well as the stability of the bond between the amino group on the silica and the SMCC molecule on the immunosorbent stability in order to develop an immunosorbent that could be used multiple times in biological buffers. 


\section{REFERENCES}

[1] Winefordnerd, J.D., (1998). High Performance Capillary Electrophoresis Chemical Analysis. Vol. 140.

[2] Wu, X. (2003) New approaches to sample preparation for capillary electrophoresis., Trends in Analytical.. Chemistry, 22, 48-58.

[3] Puig, P., Borrul, F., Calull, M., Aguilar, C. (2007). Recent advances in coupling solidphase extraction and capillary electrophoresis (SPE_CE). Trends in Analytical Chemistry, 26, 664-678.

[4] Chien, R.L., (1998) Sample Introduction and Stacking in High Performance Capillary Electrophoresis Chemical Analysis Vol. 140, Chapter 13.

[5] Fritz, J.S., Macka, M., (2000) Solid-Phase trapping of solutes for further chromatographic or electrophoretic analysis. J. Chromatography A, 902, 137-166.

[6] Saavedra, L., Barbas, C.,(2007) Chromatography-based on-and in-line preconcentration methods in capillary electrophoresis. J. Biochem. Biophys. Methods, 70, 289-297

[7] Lord, H.L., Rajab,i M., Safari, S., Pawliszyn J., (2006) Development of immunoaffinity solid phase microextraction probes for analysis of $\mathrm{sub} \mathrm{ng} / \mathrm{ml}$ concentrations of 7-aminoflunitrazepam in urine. J. Pharmaceut. Biomed. Anal. 40, 769780

[8] Bach J. Immunology., John Wiley \& Sons, New York.

[9] Harlow, E., Lane, D., (1988) Antibodies: a laboratory manual. Cold Spring Harbor Laboratory.

[10] Zhao, M., Zhou, S., Zhao, Z., Zhang, R., (2007). Characterization of the binding performance of silica-based immunoaffinity adsorbents prepared via online coupling reactions. Chromatographia, 65, 667-673.

[11] Delaunay-Bertoncini, N., Pichon, V., Hennion M.C., (2003). Experimental comparison of three monoclonal antibodies for the class-selective immunoextraction of triazines. Correlation with molecular modeling and principal component analysis studies. J. Chromatogr. A 999, 3-15.

[12] De Blas, A.L. , Sangameswaran, L., Haney, S.A., Park, D., Abraham, C.J. (Jr.), Rayner, C.A., (1985). Monoclonal Antibodies to Benzodiazepines., J. Neurochemistry., 45, 1748-1753. 
[13] Delaunay-Bertoncini, N., Pichon, V., Hennion, M.C., (2001). Comparison of immunoextraction sorbents prepared from monoclonal and polyclonal anti-isopruturon antibodies and optimization of the appropriate monoclonal antibody-based sorbent for environmental and biological applications. Chromatographia, 53, S224-S230.

[14] Pichon, V., Krasnova, A.I., Hennion, M.C., (2004). Development and characterization of an immunosorbent Solid-Phase-Extraction sorbent for trace analysis of propanil and related phenylurea herbicides in environmental waters and in beverages.Chromatographia, 60, S221-S226.

[15] Pichon, V., Chen, L., Hennion, M.C., (1995). Preparation and evaluation of immunosorbents for selective trace enrichment of phenyl urea and triazines herbicides in environmental waters. Analytical Chemistry, 67, 2451-2460.

[16] Jiang, T., Mallik, R., Hage, D.S., (2005). Affinity monoliths for ultrafast immunoextraction. Analytical Chemistry, 77, 2362-2372.

[17] Unsal, E., Durdu, A., Elmas, B., Tuncel, M., Tuncel, A., (2005). A new affinityHPLC packing for protein separation: Cibacron Blue attached uniform porous poly (HEMA-co-EDM) beads. Analytical Bioanalytical Chemistry, 383, 930-937.

[18] Rashkovetsky, L.G., Lyubarskaya, Y.V., Foret F., Hughes, D.E., and Karger, B.R.,(1997). Automated microanalysis using magnetic beads with commercial capillary electrophoretic instrumentation. J. Chromatogr. A, 781, 197-204.

[19] Chen, H-X, Busnel, J.M., Gassner, A.L., Peltre, G., Zhang, X.X., Girault, H.H. (2008).Capillary electrophoresis immunoassay using magnetic beads. Electrophoresis, $29,3414-3421$.

[20] Schiel, J., Mallik R., Soman, S., Joseph, K.S., Hage, D.S., (2006). Applications of silica supports in affinity chromatography. J. Separation Science, 29, 719-737.

[21] Weetall, H.H., (1993). Preparation of immobilized proteins covalently coupled through silane coupling agents to inorganic supports. Applied Biochemistry and Biotechnology, 41, 157-188.

[22] Ernst-Cabrera, K., Wilchek, M., (1987). Coupling of ligands to primary hydroxylcontaining silica for high-performance affinity chromatography. Optimization of conditions. J. Chromatography, 397, 187-196.

[23] Kim, H.S., Kye, Y.S., Hage, D.S., (2004). Development and evaluation of Nhydroxysuccinimide-activated silica for immobilizing human serum albumin in liquid chromatographic columns. J. Chromatography A, 1049, 51-61. 
[24] Mallik, R., Wa, C., Hage, D.S., (2007). Development of sulfhydril-reactive silica for protein immobilization in high performance affinity chromatography. Analytical Chemistry, 79, 1411-1424.

[25] Roy, S.K. Kundu, S.K., (1079). Chemically modified porous silica gel as a bioadsorbent and a biocatalysts. Analytical Biochemistry, 98, 238-241.

[26] Hermanson, G.T. (1995). Bioconjugate Techniques. Academic Press. San Diego, CA.

[27] Means, G.E., Feeney, R.E., (1990). Chemical modifications of proteins. History and applications. Bioconjugate Chemistry,1, 2-12.

[28] Brinkley, M., (1992). A brief survey of methods for preparing protein conjugates with dyes, haptens, and cross-linking reagents. Bioconjugate Chemistry, 3, 2-13.

[29] Yuan, H., Mullet, W.M., Pawlyszyn, J., (2001). Biological sample analysis with immunoaffinity solid phase extraction. Analyst, 126, 1456-1561.

[30] Wieboldt, J., Zweigenbaum, J., Henion, J., (1997). Immunoaffinity ultrafiltration with ion spray HPLC/MS for screening small-molecules libraries. Analytical Chemistry, 69, 1683-1691.

[31] Choi, J. Kim C., Choi, M.J. (1998). Immunological analysis of methamphetamine antibody and its use foe the detection of methamphetamine by capillary electrophoresis with laser-induced fluorescence. J. Chromatography B, 705, 277-282.

[32] Qi, X-H., Mi J-q., Zhang, X-X., Chang, W-B., (2005). Design and preparation of novel antibody system and application for the determination of heroin metabolites in urine by capillary electrophoresis. Analytica Chimica Acta, 551, 115-123.

[33] Deinl, I., Angermaier, L., Franzelius, C., Machbert, G., (1997). Simple highperformance liquid chromatographic column-switching technique for the on-line immunoaffinity extraction and analysis of flunitrazepam and its main metabolites in urine. J. of Chromatography B, 704, 251-258.

[34] Lord, H.L., Rajabi, M., Safari, S., Pawliszyn, J., (2007). A study of the performance characteristics of immunoaffinity solid phase microextration probes for extraction of a range of benzodiazepines. J. of Pharmaceutical and Biomedical Analysis, 44, 506-519.

[35] Sanchez, F.G., Diaz, A.N., Herrera, R.G., San Jose, L.P., (2007). Development and characterization of an immunoaffinity chromatographic column for the on-line determination of the pesticide tryclopyr. Talanta, 71, 1411-1416. 
[36] Antoni, G., Presentini, R., Neri, P., (1983). A simple method for the estimation of amino groups on insoluble matrix beads. Analytical Biochemistry, 129, 60-63.

[37] Janolino, V.G., Swaisgood, H.E., (1992). A spectrometric assay for solid phase primary amino groups. Applied Biochemistry and Biotechnology, 36, 81-85.

[38] Ngo, T.T., (1986). Colorimetric determination of reactive amino groups of a solid support using Traut's and Ellman's reagents. Applied Biochemistry and Biotechnology, $13,213-219$.

[39] Tyllianakis, P.E., Kakabakos, S.E., Evangelatos, G.P., Ithakissios, D.S., (1993).Colorimetric determination of reactive primary amino groups of macro and microsolid supports. Applied Biochemistry and Biotechnology, 38, 15-25.

[40] Farkas, P., Bystricky, S., (2010). Chemical conjugation of biomacromolecules: A mini-review., Chemical Papers, 64, 6, 683-695.

[41] Bieniarz, C., Husain, M., Barnes, G., King, C.A., Welch, C.J., (1996). Extended length heterobifunctional coupling agents for protein conjugations. Bioconjugate Chemistry, 7, 88-95.

[42] McCall, M.J., Diril, H., Meares, C.F., (1990). Simplified method for conjugation macrocyclic bifunctional chelating agents to antibodies via 2-iminothiolane. Bioconjugate Chemistry, 1, 222-226.

[43] Thermo Scientific Pierce, (2009). Protein Assay Technical Handbook. Modified Lowry Protein Assay, 27-29.

[44] Pharmacia LKB Biotechnology (1990). PhastSystem. User manual.

[45] Gupta R.K. U.S. Patent 5,164,311 (1992).

[46] Schultz, N.M., Kennedy, R.T., (1993). Rapid immunoassay using capillary electrophoresis with fluorescence detection. Analytical Chemistry, 65, 3161-3165.

[47] Habeeb, A.F.S.A., (1966). Determination of free amino groups in proteins by trinitrobenzenesulfonic acid. Analytical Biochemistry, 14, 328-336.

[48] Kakade, M.L., Liener, I.R., (1969). Determination of available lysine in proteins. Analytical Biochemistry, 27, 273-280.

[49] Thermo Scientific Pierce (2009). Antibody production technical handbook. p.9. 
[50] Delaunay-Bertoncini, N., Hennion, M.C. (2004) Immunoaffinity solid-phase extraction for pharmaceutical and biomedical trace-analysis-coupling with HPLC and CE-perspectives. J. of Pharmaceutical and Biomedical Analysis, 34, 717-736.

[51] Blas, M. and McCord, B.R., (2008). Determination of trace levels of benzodiazepine in urine using capillary electrochromatography-time of flight mass spectrometry. Electrophoresis, 29, 2182-2192.

[52] Delaunay-Bertoncini, N., Pichon, V., Hennion, M.C., (2000). Immunoaffinity solidphase extraction for the trace-analysis of low-molecular-mass analytes in complex sample matrices. J. of Chromatography B, 745, 15-37.

[53] Sato, H., Kidaka, T., Hori, M. (1987). Leakage of immobilized IgG from therapeutic immunosorbents. Applied Biochemistry and Biotechnology, 15, 145-158.

[54] Etienne, M., Walcarius, A., (2003). Analytical investigation of the chemical reactivity and stability of aminopropyl-grafted silica in aqueous medium. Talanta, 59, 1173-1188.

[55] Smith, E.A., Chen, W., (2008). How to prevent the loss of surface functionality derived from aminosilanes. Langmuir, 24, 12405-12409.

[56] Kirkland, J.J., Henderson, J.W., DeStefano, J.J., van Straten, M.A., Claessens, H.A., (1997). Stability of silica-based, endcapped column with $\mathrm{pH} 7$ and 11 mobile phases for reversed-phase high-performance liquid chromatography. J. of Chromatography A, 762, $97-112$.

[57] Claessens, H.A., van Straten, M.A., Kirkland, J.J., (1996). Effect of buffers on silica-based column stability in reversed-phase high-performance liquid chromatography. J. of Chromatography A, 728, 259-270.

[58] Mahon, E., Hristov, D.R., Dawson, K.A., (2012). Stabilizing fluorescent silica nanoparticles against dissolution effects for biological studies. Chemical Communications, 48, 7970-7972.

[59] Gomez de la Torre, T.Z., Herthnek, D., Ramachandraiah, H., Svedlindh, P., Nilsson, M., Strømme, M., (2011). Evaluation of the Sulfo-Succinimidyl-4-(N-Maleimidomethyl) Cyclohexane-1-Carboxylate coupling chemistry for attachment of oligonucleotides to magnetic nanobeads. J of Nanoscience and Nanotechnology, 11, 8532-8537.

[60] Björklund, M., Hearn, M.T.W., (1996). Synthesis of silica-based heparin-affinity adsorbents. J. of Chromatography A, 728, 149-169. 